\title{
NEW RECORDS FOR THE TURKISH FRESHWATER ALGAL FLORA IN TWENTY FIVE RIVER BASINS OF TURKEY, PART VI: CHAROPHYTA
}

\author{
Faruk MARAȘLIOĞLU ${ }^{1 *}$, Elif Neyran SOYLU², Nilsun DEMIR ${ }^{3}$, Abuzer ÇELEKLI $^{4}$, Haşim \\ SÖMEK $^{5}$, Burak ÖTERLER ${ }^{6}$, Tolga ÇETİN ${ }^{7}$, Yakup KARAASLAN ${ }^{7}$, Tuğba ONGUN \\ SEVINDIK $^{8}$, Tolga COŞKUN ${ }^{3}$, Cüneyt Nadir SOLAK ${ }^{9}$, Bengü TEMIZEL ${ }^{2}$ \\ ${ }^{1}$ Hitit University, Faculty of Arts and Science, Department of Biology, Corum, TURKEY \\ ${ }^{2}$ Giresun University, Faculty of Arts and Science, Department of Biology, Giresun, TURKEY \\ ${ }^{3}$ Ankara University, Faculty of Agriculture, Department of Fisheries and Aquaculture, Dışkapı, Ankara, TURKEY \\ ${ }^{4}$ Gaziantep University, Faculty of Art and Science, Department of Biology, Gaziantep, TURKEY \\ 5 İzmir Katip Çelebi University, Faculty of Fisheries, Department of Aquatic Sciences of Fisheries, İzmir, TURKEY \\ ${ }^{6}$ Trakya University, Balkan Campus, Faculty of Science, Department of Biology, Edirne, TURKEY \\ ${ }^{7}$ T.R. Ministry of Agriculture and Forestry, Directorate General of Water Management, Ankara, TURKEY \\ ${ }^{8}$ Sakarya University, Faculty of Arts and Science, Department of Biology, Adapazarı, TURKEY \\ ${ }^{9}$ Dumlupınar University, Faculty of Arts and Science, Department of Biology, Kütahya, TURKEY
}

Cite this article as:

Maraşlığlu F., Soylu E.N., Demir N., Çelekli A., Sömek H., Öterler B., Çetin T., Karaaslan Y., Ongun Sevindik T., Coşkun T., Solak C.N. \& Temizel B. 2021. New records for the Turkish freshwater algal flora in twenty five river basins of Turkey, part vi: Charophyta. Trakya Univ J Nat Sci, 22(2): 111-129, DOI: $10.23902 /$ trkjnat. 875740

Received: 06 February 2021, Accepted: 13 April 2021, Online First: 11 May 2021, Published: 15 October 2021

\section{Edited by: \\ Naime Arslan \\ *Corresponding Author: \\ Faruk Maraşlıŏlu \\ farukmaraslioglu@hitit.edu.tr}

\section{ORCID iDs of the authors:}

FM. orcid.org/0000-0002-7784-9243

ENS. orcid.org/0000-0002-7583-3416

ND. orcid.org/0000-0002-3895-7655

AÇ. orcid.org/0000-0002-2448-4957

HS. orcid.org/0000-0003-4281-9738

BÖ. orcid.org/0000-0002-9064-1666

TC. orcid.org/0000-0002-7817-3222

YK. orcid.org/0000-0001-8993-4771

TOS. orcid.org/0000-0001-7682-0142

TC. orcid.org/0000-0001-5732-7424

Key words:

Phytoplankton

Desmidiales

Zygnematales

First record

Lake

River Basin

\begin{abstract}
Although planktonic algae are a basic component of freshwater ecosystems, studies on their diversity and species distribution are still not in satisfactory numbers. This study aims to contribute to Turkish freshwater algal flora particularly with the new records reported. A total of 158 Charophyta taxa were determined in the study conducted from 2017 to 2019 in 25 river basins of Turkey. In this study, while the highest Charophyta taxon was found in Sakarya and Batı Akdeniz basins with 50 and 42 taxa, respectively, Burdur basin was the only basin where we did not find the Charophyta species. The highest Charophyta diversity was observed in Girdev Lake (Batı Akdeniz basin) and Işık Dağı Karagöl Lake (Sakarya basin) among the lakes of Turkey's 25 river basins. Thirty-one of these Charophyta taxa represent new records for the freshwater algal flora of Turkey. Of these, 13 species are commonly distributed, while 18 species have rare distribution areas. Morphology, ecology, and distribution of each taxon were also discussed in details.
\end{abstract}

Özet: Planktonik algler tatlı su ekosistemlerinin temel bir bileşeni olmasına rağmen, onların çeșitliliği ve tür dağılımları konusundaki çalışmalar hala tatmin edici sayılarda değildir. $\mathrm{Bu}$ çalışma, özellikle raporlanan yeni kayıtlarla Türkiye tatlı su alg florasına katkıda bulunmayı amaçlamaktadır. 2017-2019 yılları arasında Türkiye'nin 25 nehir havzasında yapılan bu çalışmada toplam 158 Charophyta taksonu tespit edilmiştir. Bu çalışmada, en yüksek Charophyta taksonuna sirasiyla 50 ve 42 takson sayısıyla Sakarya ve Batı Akdeniz havzalarında rastlanırken, Charophyta türüne rastlamadığımız tek havza Burdur olmuştur. Türkiye'nin 25 akarsu havzasındaki göller arasında en fazla Charophyta çeşitliliği Girdev Gölü (Batı Akdeniz havzası) ve Ișık Dağı Karagöl (Sakarya havzası)'de görülmüștür. Tespit edilen bu Charophyta taksonlarının 31'i Türkiye'deki tatlısu alg florası için yeni kayıt niteliğindedir. Bunlardan 13 tür yayılıș alanı olarak yaygın iken, 18 tür nadir yayılıș alanına sahiptir. Her bir taksonun morfolojisi, ekolojisi ve dağılımı da ayrıntılı olarak verilmiştir.

\section{Introduction}

In recent years, several projects funded by the Ministry of Agriculture and Forestry, Directorate General of Water Management (DGWM) and General Directorate of State Hydraulic Works (DSI) have been implemented on biological quality components of aquatic ecosystems.
The present study is a part of the "Establishment of Reference Monitoring Network in Turkey" project which is funded by DGWM. In this project, 275 lakes in 25 river basins were studied, and a total of 1363 phytoplankton taxa of which 158 belong to Charophyta were determined. 
Among the determined species, new records were reported, in addition to already reported taxa, for Turkish flora. Most of the Charophyta taxa that were identified in our study belong to the order Desmidiales, as seen in many studies.

The most Charophyta taxa identified in the lakes within 25 river basins belong to the order Desmidiales, as seen in many previous similar studies (Shukla et al. 2008, Oliveira et al. 2010, Hansen et al. 2018). Desmids are exclusively found in freshwater habitats (Kouwets 2008) and usually prefer acidic or $\mathrm{pH}$-circumneutral, nutrientpoor, and clear waters (Lenzenweger 1996). According to Şahin and Akar (2019), desmid flora is typical, with a predominance of cosmopolitan species, planktic-benthic forms, acidophilic and $\mathrm{pH}$-indifferent species, and halophobic-to-salinity-indifferent species. It is well known that Desmidiales members, which attracted the attention of scientists due to their forms, exhibit great diversity in their external morphology and show a remarkably complex cell symmetry (Lee 2015). Desmids are also considered excellent bioindicators in terms of the stability of ecosystems (Coesel 1998). In recent years, eutrophication, acidification, desiccation, and cultivation have been identified as processes that could negatively affect desmid habitats (Lenzenweger 1996, Šimek 1997 , Coesel et al. 1978, Štastný 2009).

Turkish inland waters have quite rich algal diversity with 3690 taxa determined so far (Taşkın et al. 2019). However, the number of Charophyta members listed in algaebase (4906 taxa) are more than the total number of algal taxa in Turkey (Guiry \& Guiry 2021). The number of Charophyta members identified in Turkish freshwaters is only 385 (Taşkın et al. 2019). However, 186 desmid species were detected only in four different localities on the Danish island Bornholm (Hansen et al. 2018). Thus, more studies are needed to contribute to completion of the list of algal flora of Turkey. A few checklists containing the algae determined in several studies on freshwater algal flora of Turkey were published by Gönülol et al. (1996), Aysel (2005) and Şahin (2005) and new taxa records were given during studies performed in the last couple of decades (Aysel et al. 1993, Öztürk et al. 1995a, 1995b, Şahin 1998, 2000, 2002, 2007, 2009, Apaydın-Yağc1 \& Turna 2002, Atıc1 2002, Şahin \& Akar 2007, Baykal et al. 2009, Sevindik et al. 2010, 2011, 2015, 2017; Bekleyen et al. 2011, Özer et al. 2012, Akar \& Şahin 2014, Yüce \& Ertan 2014, Varol \& Fucikova 2015, Varol \& Şen 2016, Maraşlığlu \& Soylu 2018, Şahin \& Akar 2019, Şahin et al. 2020).

The studies mentioned above were conducted in different wetlands in Turkey and provided a great contribution to the determination of freshwater algal flora of Turkey and to the checklists published earlier. Reliable descriptive information was also given in these publications about the new records. The aim of the study is to determine the algal flora of Turkish freswater in selected 25 river basins.

\section{Materials and Methods}

\section{Study Area}

Turkey has 25 river basins (Fig. 1, Table 1), and inland water bodies in these basins consisting of 200 natural lakes, 806 reservoirs and 1000 irrigation ponds. The general directorate of state ydraulic works of Turkey (DSI) data show that the volume of annual average precipitation is estimated to be 501 billion $\mathrm{m}^{3}$ water, of which about $55 \%$ is lost by evapotranspiration, $31 \%$ flows into water bodies $\left(158\right.$ billion $\mathrm{m}^{3}$ ) and $14 \%$ feeds aquifers $\left(69\right.$ billion $\left.\mathrm{m}^{3}\right)$. The Frrat-Dicle Basin provides the largest single volume of available exploitable freshwater resources in Turkey, representing $28.5 \%$ of the total (DSİ 2014).

A total of 275 lakes, including reservoirs, were sampled during the study in 25 river basins. The number of studied lakes considering the river basins were given in Table 1. These lakes, located between the longitudes of $26^{\circ} 19^{\prime}$ and $43^{\circ} 54^{\prime} \mathrm{E}$ and the latitudes of $35^{\circ} 56^{\prime}$ and $42^{\circ}$ $00^{\prime} \mathrm{N}$, are grouped in 22 lake typologies based on altitude (R), lake depth (D), lake size (A), and geology (J) (DGWM 2015a). The altitudes of the sampled lakes vary from sea level (Lake Gala) to $2757 \mathrm{~m}$ (Lake Çamlu).

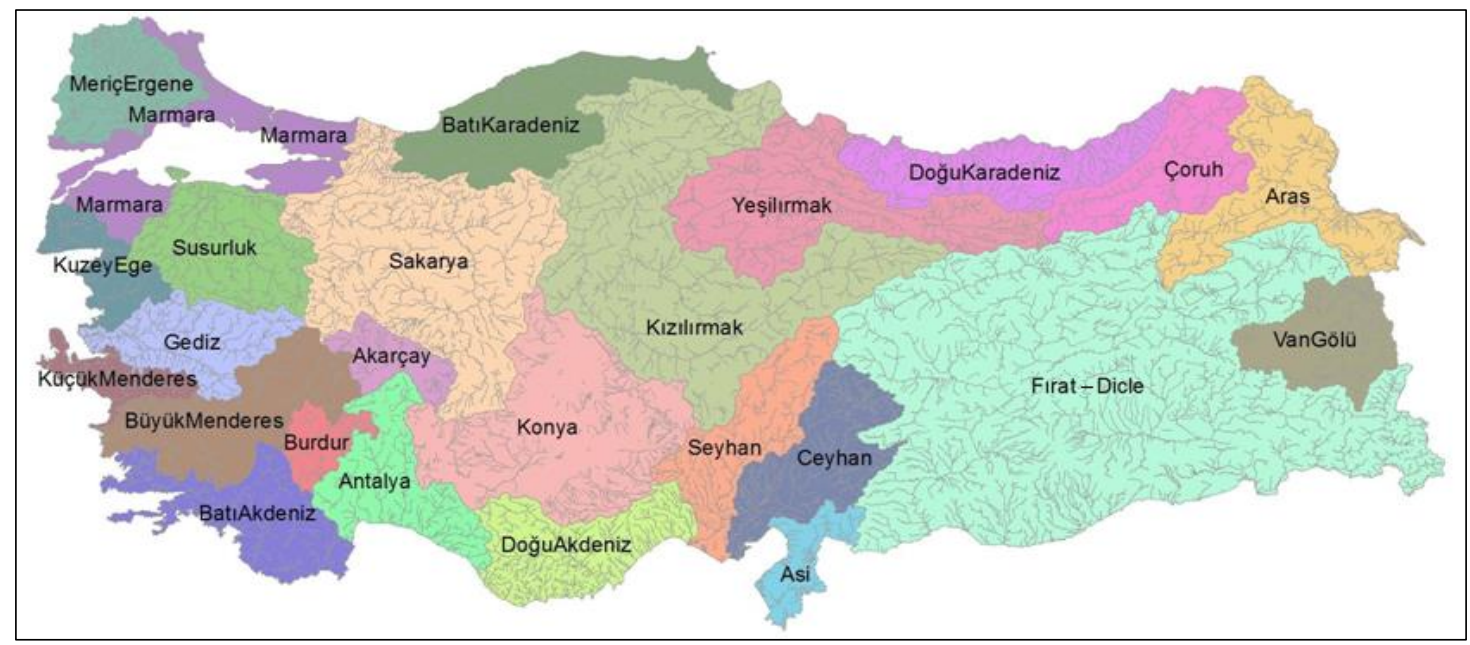

Fig. 1. 25 River basins in Turkey. 
Table 1. The number and names of sampled lakes in the 25 river basins.

\begin{tabular}{|c|c|c|c|}
\hline No & Basin & $\begin{array}{l}\text { The number of } \\
\text { studied lakes }\end{array}$ & Name of lake \\
\hline 1 & Akarçay & 10 & $\begin{array}{l}\text { (1) Akşehir Lake, (2) Eber Lake, (3) Akdeğirmen Reservoir, (4) } 26 \text { Ağustos TP } \\
\text { Lake, (5) Karamık Reeds, (6) Ağzıkara Pond, (7) Tınaztepe Pond, (8) Gezler Pond, } \\
\text { (9) Şehit Uz. Çvş. Nurullah Oymak Pond, (10) Tazlar Satı Gelin Pond }\end{array}$ \\
\hline 2 & Antalya & 9 & $\begin{array}{l}\text { (11) Eğirdir Lake, (12) Kovada Lake, (13) Gölcük Lake, (14) Cemalalanı Lake, } \\
\text { (15) Duruca Lake, (16) Eğri Lake, (17) Küllü Lake, (18) Titreyen Lake, (19) Düden } \\
\text { Lake }\end{array}$ \\
\hline 3 & Aras & 3 & (20) Aktaş Lake, (21) Çıldır Lake, (22) Aygır Lake \\
\hline 4 & Asi & 8 & $\begin{array}{l}\text { (23) Reyhanlı (Yenihisar) Lake, (24) Yayladağ Reservoir, (25) Tahtaköprü } \\
\text { Reservoir, (26) Karagöl Lake, (27) Adsı Lake, (28) Yarseli Reservoir, (29) } \\
\text { Üçpınar Pond, (30) Sapkanlı Pond }\end{array}$ \\
\hline 5 & Batı Akdeniz & 13 & $\begin{array}{l}\text { (31) Gölhisar Lake, (32) Girdev Lake, (33) Avlan Lake, (34) Dalaman Wetlands, } \\
\text { (35) Denizcik Lake, (36) Kocagöl Lake, (37) Kusuru Lake, (38) Köycegiz Lake, } \\
\text { (39) Küçükdalyan Lake, (40) Yeşilgöl Lake, (41) Yazır Lake, (42) Baranda Lake, } \\
\text { (43) Pozan Lake }\end{array}$ \\
\hline 6 & Batı Karadeniz & 14 & $\begin{array}{l}\text { (44) Nazlı Lake, (45) Büyük Lake, (46) Derin Lake, (47) Parçayır Lake, (48) Abant } \\
\text { Lake, (49) Dipsiz Lake, (50) Gölcük Lake, (51) Keçi Lake, (52) Yeniçağa Lake, } \\
\text { (53) Kuyudüzü Lake, (54) Erze Lake, (55) Koca Lake, (56) Kuru Lake Natural } \\
\text { Park, (57) Sazlı Lake }\end{array}$ \\
\hline 7 & Burdur & 6 & $\begin{array}{l}\text { (58) Acıgöl Lake, (59) Burdur Lake, (60) Karataş Lake, (61) Salda Lake, (62) } \\
\text { Tefenni Pond, (63) Keçiborlu Güneykent Uzundere Pond }\end{array}$ \\
\hline 8 & Büyük Menderes & 13 & $\begin{array}{l}\text { (64) Işıkı Lake, (65) Bafa Lake, (66) Azap Lake, (67) Karakuyu Reeds, (68) } \\
\text { Süleymanlı Lake, (69) İkizdere Reservoir, (70) Gerenlik Lake, (71) Gökgöl Lake, } \\
\text { (72) Gökpınar Reservoir, (73) Karacasu Reservoir, (74) Karagöl Lake, (75) Saklı } \\
\text { Lake, (76) Sülüklü Lake }\end{array}$ \\
\hline 9 & Ceyhan & 18 & $\begin{array}{l}\text { (77) Gölbaşı Lake, (78) Kartalkaya Reservoir, (79) Kara Lake, (80) B. Yapalak } \\
\text { Pond, (81) Korkmaz Pond, (82) Zorkun Pond, (83) Merk Pond, (84) Yamaçoba } \\
\text { Pond, (85) Kızıliniş Pond, (86) Arıklıkaş Pond, (87) Karacaören Pond, (88) } \\
\text { Meletmez Pond, (89) Postkabasakal Pond, (90) Bağtepe Pond, (91) Zerdali Pond, } \\
\text { (92) Kozan Aydın Pond, (93) Yumurtalık Zeytinbeli Pond, (94) Yumurtalık } \\
\text { Ayvalık Pond }\end{array}$ \\
\hline 10 & Çoruh & 8 & $\begin{array}{l}\text { (95) Adsız Lake, (96) Boğa Lake, (97) Balık Lake, (98) Şavşat Karagöl Lake, (99) } \\
\text { Çil Lake, (100) Borçka Karagöl Lake, (101) Tortum Lake, (102) Ürünlü Pond }\end{array}$ \\
\hline 11 & Doğu Akdeniz & 12 & $\begin{array}{l}\text { (103) Aygır Lake, (104) Uzun Lake, (105) Değirmendere Pond, (106) Cemilli } \\
\text { Çevlik Pond, (107) Hacınuhlu Kelce Pond, (108) Akın Pond, (109) Kızı̈̈z Pond, } \\
\text { (110) Başyayla Pond, (111) Göktepe Pond, (112) Bağbaşı Reservoir, (113) } \\
\text { Yassıbağ Pond, (114) Hadım-İnönü Pond }\end{array}$ \\
\hline 12 & Doğu Karadeniz & 7 & $\begin{array}{l}\text { (115) Gaga Lake, (116) Sera Lake, (117) Ulugöl Lake, (118) Uzungöl Lake, (119) } \\
\text { Çamlu Lake, (120) Çakır Lake, (121) Limni Lake }\end{array}$ \\
\hline 13 & Firat-Dicle & 17 & $\begin{array}{l}\text { (122) Kaz Lake, (123) Ahır Lake, (124) Haçlı Lake, (125) Korlu Lake, (126) Hazar } \\
\text { Lake, (127) Karagöl Lake, (128) Yeşildere Pond, (129) Palandöken Pond, (130) } \\
\text { Güroymak Reservoir, (131) Kalecik Reservoir, (132) Kapıçmaz Pond, (133) } \\
\text { Dedeyolu Pond, (134) Güzelyurt Sulama Pond, (135) Hasancık Pond, (136) İncesu } \\
\text { Pond, (137) Otlukbeli Lake, (138) Siverek Yeleken Pond }\end{array}$ \\
\hline 14 & Gediz & 6 & $\begin{array}{l}\text { (139) Gölcük Lake, (140) Demirköprü Reservoir, (141) Marmara Lake, (142) } \\
\text { Gördes Reservoir, (143) Karagöl Lake, (144) Küçükler Reservoir }\end{array}$ \\
\hline 15 & Kızılırmak & 23 & $\begin{array}{l}\text { (145) Gölbel Lake, (146) Ulaş Lake-2, (147) Büyük Lota Lake, (148) Hafik Lake, } \\
\text { (149) Küçük Lota Lake, (150) Tödürge Lake, (151) Arı Lake, (152) Aygır Lake, } \\
\text { (153) Bakkal Lake, (154) Dipsiz Lake, (155) Elekci Lake, (156) Ulaş Lake-1, (157) } \\
\text { Ulaş Lake-3, (158) Deniz Lake, (159) Yeşilgöl 1 Lake, (160) Bardakçılı Mevki } \\
\text { Lake, (161) Yenidanişment Mevki Lake, (162) Palanga Lake, (163) Sugiylan } \\
\text { Mevki Lake, (164) Kayabaşı Lake, (165) Kuru Lake, (166) Sıraç Lake, (167) } \\
\text { Kızılçam Lake }\end{array}$ \\
\hline 16 & Konya & 18 & $\begin{array}{l}\text { (168) Sarıt Lake, (169) Beyşehir Lake, (170) Tuz Lake, (171) Süleymanhacı Lake, } \\
\text { (172) Gök (Kozanlı) Lake, (173) Meke Lake (Meke Maarı), (174) Gavur Lake, } \\
\text { (175) Dipsiz Lake, (176) Acıgöl Lake 2, (177) Bakı Lake, (178) Uyuz Lake, (179) } \\
\text { Acıgöl Lake 1, (180) Kayı Lake, (181) Düden Lake, (182) Kovalı Lake, (183) } \\
\text { Köpek Lake, (184) Küçük Lake, (185) Sülüklü Lake }\end{array}$ \\
\hline
\end{tabular}


Table 1. Continued.

\begin{tabular}{|c|c|c|c|}
\hline No & Basin & $\begin{array}{c}\text { The number of } \\
\text { studied lakes }\end{array}$ & Name of lake \\
\hline 17 & Kuzey Ege & 5 & $\begin{array}{l}\text { (186) Boz Lake, (187) Güzelhisar Reservoir, (188) Karagöl Lake, (189) Sevişler } \\
\text { Reservoir, (190) Tepe Lake }\end{array}$ \\
\hline 18 & Küçük Menderes & 6 & $\begin{array}{l}\text { (191) Çatal Lake, (192) Tahtalı Reservoir, (193) Alaçatı Barajı, (194) Belevi Lake, } \\
\text { (195) Gebekirse Lake, (196) Ürkmez Reservoir }\end{array}$ \\
\hline 19 & Marmara & 9 & $\begin{array}{l}\text { (197) Habibler Mevki Pond, (198) Great Dipsiz Lake, (199) İznik Lake, (200) Koca } \\
\text { Lake, (201) Karamaden Lake, (202) Danamandıra Lake-1, (203) Danamandıra } \\
\text { Lake-2, (204) Small Dipsiz Lake, (205) Sinekli Lake }\end{array}$ \\
\hline 20 & Meriç-Ergene & 5 & $\begin{array}{l}\text { (206) Gala Lake, (207) Sı̆̆ırcı Lake, (208) Pamuklu Lake, (209) Üsküp Sulama } \\
\text { Pond, (210) Domuz Lake }\end{array}$ \\
\hline 21 & Sakarya & 23 & $\begin{array}{l}\text { (211) Taşkısı̆ğ Lake, (212) Akgöl } 2 \text { Lake, (213) Çubuk Lake, (214) Poyrazlar } \\
\text { Lake, (215) Sapanca Lake, (216) Işı Dağı Karagöl Lake, (217) Çavuşcu Lake, } \\
\text { (218) Mogan Lake, (219) Üçlerkayası Pond, (220) Çubuk Karagöl Lake, (221) } \\
\text { Eymir Lake, (222) Akgöl 1 Lake, (223) Küçük Akgöl Lake, (224) Avdan Lake, } \\
\text { (225) Kayuslu Lake, (226) Karamurat Lake, (227) Cüneyt Sönmez Pond, (228) } \\
\text { Çılgınlar Pond, (229) Yıldırım Evci Pond, (230) Ovacık Lake, (231) Sülüklü Lake, } \\
\text { (232) Çamkoru TP Pond, (233) Anagöl Lake }\end{array}$ \\
\hline 22 & Seyhan & 12 & $\begin{array}{l}\text { (234) Bahçelik Reservoir, (235) Tufanbeyli Demiroluk Pond, (236) Adsız Lake, } \\
\text { (237) Pekmezli-Çatalçam Pond, (238) Tufanbeyli Doğanbeyli Pond, (239) } \\
\text { Gümüşören Reservoir, (240) Şılılı Pond, (241) Dölekli Pond, (242) Kılıçlı Pond, } \\
\text { (243) Topacık Pond, (244) Hüsniye Pond, (245) Çavuşlu Pond }\end{array}$ \\
\hline 23 & Susurluk & 9 & $\begin{array}{l}\text { (246) Manyas Lake, (247) Uluabat Lake, (248) Adsı-1 Lake, (249) Gölbaşı Lake, } \\
\text { (250) Gölcük Lake, (251) İkizcetepeler Reservoir, (252) Karagöl Lake, (253) } \\
\text { Kilimli Lake, (254) Nilüfer Reservoir }\end{array}$ \\
\hline 24 & Van Gölü & 7 & $\begin{array}{l}\text { (255) Akgöl Lake, (256) Erçek Lake, (257) Bostaniçi Pond, (258) Arin Lake, (259) } \\
\text { Aygır Lake, (260) Van Lake, (261) Nazik Lake }\end{array}$ \\
\hline 25 & Yeşilırmak & 14 & $\begin{array}{l}\text { (262) Akgöl Lake, (263) Aşağıtepecik (Gölova) Lake, (264) Boraboy Göleti, (265) } \\
\text { Büyük Lake, (266) Düden Lake, (267) Kaz Lake, (268) Ladik Lake, (269) Uyuz } \\
\text { Lake, (270) Karacaören Mevki Lake, (271) Dipsiz Lake 2, (272) Sarıçiçek Lake, } \\
\text { (273) Yenihayat Reservoir (274) Dipsiz Lake 1, (275) Zinav Lake }\end{array}$ \\
\hline
\end{tabular}

\section{$\underline{\text { Sampling and Identification }}$}

Phytoplankton was sampled annually from 2017 to 2019 in three seasons (spring, summer and autumn) at monitoring station(s) in each lake. The number of monitoring points (station) in the lakes varied according to the lake areas determined by the general directorate of water management. According to this, sampling point numbers were determined as 1 for lakes that have a surface area smaller than 50 ha, 2 for lakes that have a surface area between 50 and 500 ha and, 3 for lakes which have a surface area higher than 500 ha (DGWM 2015b). One of the selected stations was determined at the deepest point of the lake. No bathymetric study was carried out in the lakes, and the deepest point of the lake was determined through a depth meter. Three depths (surface, middle, and bottom) of the euphotic depth (Secchi disk depth $\times 2.5$ ) were sampled with a Ruttner water sampler (HydroBios $2 \mathrm{~L}, 0.5 \mathrm{~m}$ long), then a subsample was taken from mixed water of the three depths. Plankton net with a pore diameter of $50 \mu \mathrm{m}$ was also used for sampling. Samples were fixed with Lugol's solution. Identification of the algal taxa was performed with compound and inverted microscopes according to the literature (Kolkwitz \& Krieger 1971, Lind \& Brook 1980, Huber-Pestalozzi
1982, Kadlubowska 1984, Lenzenweger 1996, 1997, 1999, 2003, Compère 2001, John et al. 2003, Coesel \& Meesters 2007). Identified taxa were checked with the checklist of Aysel (2005), Taşkın et al. (2019), and the database of Turkish algae (Maraşlığlu \& Gönülol 2021). The currently accepted nomenclature and distribution of taxa were given according to Guiry \& Guiry (2021). The author names were abbreviated according to Brummit \& Powell (1992). Taxa were photographed with a camera attached to the microscopes. List of Charaophyta taxa, the basin and lakes they were obtained are given in Table 2. Species name, synonym, description, ecology, distributional data and obtained basin and lakes information are given only for new taxa in the result section.

\section{Results}

A total of 158 Charophyta taxa, of which 31 are new records for the freshwater algal flora of Turkey were determined during the whole study (Table 2). Thity-one taxa from Charophyta were detected as new records for the freshwater algal flora of Turkey in this comprehensive study. 30 of the new records were found to be members of the order Desmidiales and 1 of the order Zygnematales. Morphotaxonomic description, ecology, and distribution of each of these taxa are given below. 
Table 2. List of Charophyta taxa (Italic numbers show Basin names in Table 1, bold numbers show lake names in Table 1).

\begin{tabular}{|c|c|c|c|}
\hline \multirow{2}{*}{ No } & \multirow{2}{*}{ Taxa } & \multicolumn{2}{|r|}{ Localities } \\
\hline & & $\operatorname{Basin}(\mathbf{s})$ & Lake(s) \\
\hline 1 & $\begin{array}{l}\text { Actinotaenium wollei (West \& G.S.West) Teiling ex Ruzicka } \\
\& \text { Pouzar } 1978^{*}\end{array}$ & 23 & 246 \\
\hline 2 & Closterium acerosum Ehrenb. ex Ralfs 1848 & $2,16,18$ & $12,17,182,194$ \\
\hline 3 & Closterium aciculare T.West 1860 & $16,17,18,19,23,25$ & $\begin{array}{l}169,177,182,185,189,186,187,193,197 \\
199,201,202,246,249,251,274,271\end{array}$ \\
\hline 4 & Closterium acutum Bréb. 1848 & $16,17,20,21,23,25$ & $174,189,208,216,251,266,275$ \\
\hline 5 & Closterium acutum var. linea (Perty) West \& G.S.West 1900 & 21 & 216 \\
\hline 6 & $\begin{array}{l}\text { Closterium acutum var. variabile (Lemmerm.) Willi Krieg. } \\
1935\end{array}$ & $1,4,5,13,21$ & $8,10,28,31,42,122,124,129,211,219$ \\
\hline 7 & Closterium dianae Ehrenb. ex Ralfs 1848 & $2,5,8,11,21,25$ & $17,41,64,103,216,269,271$ \\
\hline 8 & Closterium dianae var. rectius (Nordst.) De Toni 1977* & 1 & 2 \\
\hline 9 & Closterium ehrenbergii Menegh. ex Ralfs 1848 & 18 & 194 \\
\hline 10 & Closterium gracile Bréb. ex Ralfs 1848 & 2,10 & 12,99 \\
\hline 11 & Closterium idiosporum West \& G.S.West 1900 & 21 & 216 \\
\hline 12 & Closterium jenneri var. cynthia (De Not.) Petlovany 2015 & 21 & 216,219 \\
\hline 13 & Closterium kuetzingii Bréb. 1856 & 15 & 162 \\
\hline 14 & Closterium leibleinii Kütz. ex Ralfs 1848 & 15 & 162 \\
\hline 15 & Closterium limneticum Lemmerm. 1899 & 13,21 & $129,131,138,232,225$ \\
\hline 16 & Closterium littorale Gay 1884 & $9,14,16,19,20,23$ & $\begin{array}{l}78,140,141,144,185,199,208,210,206, \\
246\end{array}$ \\
\hline 17 & Closterium lunula Ehrenb. \& Hemprich ex Ralfs 1848 & $9,14,17,20,23$ & $84,140,189,206,208,246,251$ \\
\hline 18 & Closterium moniliferum Ehrenb. ex Ralfs 1848 & 16,22 & 174,234 \\
\hline 19 & Closterium navicula (Bréb.) Lütkem. 1905 & 2,10 & 12,99 \\
\hline 20 & Closterium parvulum Nägeli 1849 & 8,16 & 67,174 \\
\hline 21 & Closterium pronum Bréb. 1856 & 5 & 40,42 \\
\hline 22 & Closterium pseudolunula O.Borge 1909 & 1 & 2 \\
\hline 23 & Closterium pygmaeum Gutw. 1890* & 21 & 224 \\
\hline 24 & Closterium strigosum Bréb. 1856 & 19 & 205 \\
\hline 25 & Cosmarium abbreviatum Racib. 1885 & $4,21,25$ & $28,216,269$ \\
\hline 26 & Cosmarium asphaerosporum Wittr. 1879 & 19 & 202 \\
\hline 27 & Cosmarium berryense Kouwets 1998 & 21 & 225 \\
\hline 28 & Cosmarium bioculatum Bréb. ex Ralfs 1848 & $4,11,14,16,17,25$ & $28,104,110,140,174,189,263$ \\
\hline 29 & $\begin{array}{l}\text { Cosmarium bioculatum var. depressum (Schaarschm.) } \\
\text { Schmidle } 1894\end{array}$ & 1,21 & $10,213,219,232$ \\
\hline 30 & Cosmarium bireme G.S.West 1904 & 1,13 & 6,134 \\
\hline 31 & Cosmarium blyttii Wille 1880 & 24,25 & 258,272 \\
\hline 32 & Cosmarium boeckii Wille 1880 & 16 & 175 \\
\hline 33 & Cosmarium botrytis Menegh. ex Ralfs 1848 & $2,14,17,19,20,23$ & $17,140,141,188,202,206,251$ \\
\hline 34 & Cosmarium brebissonii Menegh. ex Ralfs 1848* & 5 & 32 \\
\hline 35 & Cosmarium cataractarum (Racib.) B.Eichler 1895 & 4 & 29 \\
\hline 36 & Cosmarium clepsydra Nordst. 1870 & 19,20 & 199,210 \\
\hline 37 & Cosmarium contractum O.Kirchner 1878 & 2,5 & 12,33 \\
\hline 38 & Cosmarium contractum var. rotundatum Borge $1925^{*}$ & 15 & 149 \\
\hline 39 & Cosmarium contractum var. minutum (Delponte) Coesel 1989 & 13 & 133 \\
\hline 40 & Cosmarium crenatum Ralfs ex Ralfs 1848 & 10 & 97 \\
\hline
\end{tabular}


Table 2. Continued.

\begin{tabular}{|c|c|c|c|}
\hline \multirow[b]{2}{*}{ No } & \multirow{2}{*}{ Taxa } & \multicolumn{2}{|r|}{ Localities } \\
\hline & & $\operatorname{Basin}(\mathbf{s})$ & Lake(s) \\
\hline 41 & Cosmarium cymatonotophorum West 1892 & 21 & $213,227,228$ \\
\hline 42 & Cosmarium depressum var. planctonicum Reverdin 1919 & 15,21 & 149,213 \\
\hline 43 & Cosmarium difficile Lütkem. 1892 & 4,21 & 28,216 \\
\hline 44 & Cosmarium distentum (West) Coesel \& Meesters 2015* & 5,21 & 32,214 \\
\hline 45 & Cosmarium formosulum Hoff 1888 & 2 & 12,15 \\
\hline 46 & Cosmarium galeritum Nordst. 1870 & 15 & $148,149,158$ \\
\hline 47 & Cosmarium granatum Bréb. ex Ralfs 1848 & 2,16 & 11, 176, 177 \\
\hline 48 & Cosmarium humile Nordst. ex De Toni 1889 & $5,10,15,19,21,25$ & $32,99,159,199,216,272$ \\
\hline 49 & $\begin{array}{l}\text { Cosmarium humile var. substriatum (Nordst.) Schmidle } \\
\text { 1895* }\end{array}$ & 5,10 & 33,99 \\
\hline 50 & Cosmarium impressulum Elfving 1881 & 5 & 32 \\
\hline 51 & $\begin{array}{l}\text { Cosmarium impressulum var. crenulatum (Nägeli) Willi } \\
\text { Krieg. \& Gerloff } 1965^{*}\end{array}$ & 15 & 162 \\
\hline 52 & Cosmarium laeve Rabenh. 1868 & $\begin{array}{l}2,4,5,6,11,13,15 \\
16,20,21\end{array}$ & $\begin{array}{l}11,16,27,32,35,48,104,105,106,107 \\
132,133,147,149,176,185,206,224,225\end{array}$ \\
\hline 53 & $\begin{array}{l}\text { Cosmarium mamilliferum var. madagascariense West \& } \\
\text { G.S.West } 1885^{*}\end{array}$ & 13 & 126 \\
\hline 54 & Cosmarium meneghinii Bréb. ex Ralfs 1848 & $4,5,10,21,24$ & $26,32,99,216,261$ \\
\hline 55 & Cosmarium moniliforme Ralfs 1848 & $1,8,13,21$ & $5,64,132,215,219$ \\
\hline 56 & Cosmarium neodepressum G.J.P.Ramos \& C.W.N. Moura 2020 & $3,5,6,15,22$ & $22,32,54,55,57$ \\
\hline 57 & $\begin{array}{l}\text { Cosmarium norimbergense var. depressum (West \& } \\
\text { G.S.West) Willi Krieg. \& Gerloff } 1969\end{array}$ & 5,21 & $32,227,232$ \\
\hline 58 & Cosmarium nymannianum Grunov 1868* & 2 & 19 \\
\hline 59 & Cosmarium obtusatum (Schmidle) Schmidle 1898 & 5 & 32 \\
\hline 60 & Cosmarium ornatum Ralfs ex Ralfs 1848 & 9 & 86 \\
\hline 61 & Cosmarium phaseolus Bréb. ex Ralfs 1848 & 13,21 & 132,229 \\
\hline 62 & Cosmarium phaseolus var. subbireme Racib. 1889 & 21 & 216 \\
\hline 63 & Cosmarium polygonatum Halász 1940 & 5,21 & $33,214,216,219,224$ \\
\hline 64 & Cosmarium pseudowembaerense Kouwets 1998* & 5,13 & 33,131 \\
\hline 65 & Cosmarium punctulatum Bréb. 1856 & $8,12,14,20$ & $64,115,140,206$ \\
\hline 66 & Cosmarium pygmaeum W.Archer 1864 & $5,10,16$ & $32,100,175$ \\
\hline 67 & Cosmarium quinarium Lundell 1871* & 21 & 224 \\
\hline 68 & Cosmarium regnellii Wille 1884 & 5,21 & $32,216,218,219,227,228$ \\
\hline 69 & Cosmarium regnesi Reinsch 1866 & 5,21 & 32,216 \\
\hline 70 & Cosmarium reniforme (Ralfs) W.Archer 1874 & 5,25 & $32,271,275$ \\
\hline 71 & Cosmarium reniforme var. compressum Nordst. 1887 & 8,21 & 64,216 \\
\hline 72 & Cosmarium speciosum Lundell 1871 & 2 & 15 \\
\hline 73 & Cosmarium sphagnicola West \& G.S.West 1897* & 5 & 32 \\
\hline 74 & Cosmarium sportella Bréb. ex Kütz. 1849 & 16 & 169 \\
\hline 75 & Cosmarium subadoxum Grönblad* & $4,13,21$ & $28,29,132,135,214$ \\
\hline 76 & Cosmarium subcostatum Nordst. 1876 & 2,25 & 19,269 \\
\hline 77 & $\begin{array}{l}\text { Cosmarium subcostatum var. minus (West \& G.S.West) Kurt } \\
\text { Först.1981 }\end{array}$ & 5 & 33 \\
\hline 78 & Cosmarium subcrenatum Hantzsch 1868 & 10,17 & 99, 189 \\
\hline 79 & Cosmarium subgranatum (Nordst.) Lütkem. 1902* & 21 & 224,225 \\
\hline
\end{tabular}


Table 2. Continued.

\begin{tabular}{|c|c|c|c|}
\hline \multirow[b]{2}{*}{ No } & \multirow[b]{2}{*}{ Taxa } & \multicolumn{2}{|r|}{ Localities } \\
\hline & & $\operatorname{Basin}(\mathbf{s})$ & Lake(s) \\
\hline 80 & "Cosmarium subprotumidum Nordst. 1876 & 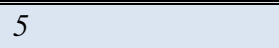 & 32 \\
\hline 81 & Cosmarium subquadrans West \& G.S.West 1905* & 4 & 28,29 \\
\hline 82 & Cosmarium subquadrans var. minus Nordst. 1873* & 21 & 215 \\
\hline 83 & Cosmarium subtumidum Nordst. 1878 & 5 & 35 \\
\hline 84 & $\begin{array}{l}\text { Cosmarium subtumidum var. minutum (Willi Krieg.) Willi } \\
\text { Krieg. \& Gerloff } 1965\end{array}$ & 5,13 & 33,133 \\
\hline 85 & Cosmarium subundulatum Wille 1880 & 15 & 148 \\
\hline 86 & Cosmarium tenиe W.Archer 1868 & 13 & 132 \\
\hline 87 & Cosmarium tetrachondrum Lundell 1871* & 5 & 32 \\
\hline 88 & Cosmarium tinctum Ralfs 1848 & $2,4,5,13,16,21$ & $12,30,37,133,136,138,176,185$ \\
\hline 89 & Cosmarium venustum (Bréb.) Archer 1861 & 16,25 & 174,271 \\
\hline 90 & Cosmarium wembaerense Schmidle 1898 & 1,21 & 2,218 \\
\hline 91 & Cylindrocystis brebissonii (Ralfs) De Bary 1858 & 2 & 19 \\
\hline 92 & Desmidium aptogonum Bréb. ex Kütz. 1849 * & 8 & 67 \\
\hline 93 & Elakatothrix gelatinosa Wille 1898 & $\begin{array}{l}1,3,5,10,12,13,16 \\
21,25\end{array}$ & $\begin{array}{l}3,9,22,32,35,42,95,115,117,129,131 \\
130,134,135,175,211,214,227,231,232 \\
213,216,225,264,265,275,274,271,273\end{array}$ \\
\hline 94 & Euastrum lacustre (Messik.) Coesel 1984* & 15 & 148 \\
\hline 95 & Gonatozygon brebissonii De Bary 1858 & 2,11 & 11,104 \\
\hline 96 & Gonatozygon monotaenium De Bary 1856 & 5 & 35 \\
\hline 97 & Groenbladia undulata (Nordst.) Kurt Först.1973* & 21 & 222 \\
\hline 98 & Heimansia pusilla (Hilse) Coesel 1993 & 1 & 6,8 \\
\hline 99 & Hormidiopsis crenulata (Kütz.) Heering 1914 & 2 & 15 \\
\hline 100 & Micrasterias furcata C.Agardh ex Ralfs 1848* & 21 & 216 \\
\hline 101 & Micrasterias rotata Ralfs 1848 & 10 & 99 \\
\hline 102 & Mougeotia boodlei (West \& West) Collins 1912 & 2,16 & $12,13,169,174,175,176,182$ \\
\hline 103 & Mougeotia capucina C.Agardh 1824 & 17,23 & 187,249 \\
\hline 104 & Mougeotia nummuloides (Hassall) De Toni 1889 & 2 & 15 \\
\hline 105 & Mougeotia parvula Hassall 1843 & 2 & 11,19 \\
\hline 106 & Mougeotia quadrangulata Hassall 1843 & 2,16 & $11,17,175,178,182$ \\
\hline 107 & Mougeotia varians (Wittr.) Czurda 1932 & 5 & 32 \\
\hline 108 & Mougeotia viridis (Kütz.) Wittr. 1872 & $14,16,17,19$ & $142,180,189,199$ \\
\hline 109 & Pleurotaenium trabecula Nägeli 1849 & 2,4 & 13,26 \\
\hline 110 & Roya closterioides Coesel 2007 & 21 & 216 \\
\hline 111 & Spirogyra aequinoctialis West 1907 & 22 & 239 \\
\hline 112 & Spirogyra cataeniformis (Hassall) Kütz. 1849 & 2,16 & 19,176 \\
\hline 113 & Spirogyra communis (Hassall) Kütz. 1849 & 16 & 176 \\
\hline 114 & Spirogyra dubia Kütz. 1849 & 16 & 176 \\
\hline 115 & Spirogyra decimina var. elongata (Vaucher) Petlovany 2015* & 2 & 11 \\
\hline 116 & Spirogyra rivularis (Hassall) Rabenh. 1868 & 2 & 19 \\
\hline 117 & Spirogyra weberi Kütz. 1843 & 2 & $11,13,15$ \\
\hline 118 & Spondylosium panduriforme (Heimerl) Teiling 1957* & 13 & 132 \\
\hline 119 & Staurastrum alternans Bréb. 1848 & 20,23 & 206,251 \\
\hline
\end{tabular}


Table 2. Continued.

\begin{tabular}{|c|c|c|c|}
\hline \multirow{2}{*}{ No } & \multirow{2}{*}{ Taxa } & \multicolumn{2}{|r|}{ Localities } \\
\hline & & $\operatorname{Basin}(\mathbf{s})$ & Lake(s) \\
\hline 120 & Staurastrum anatinum Cooke \& Wills 1881 & 8 & 73 \\
\hline 121 & Staurastrum avicula var. lunatum (Ralfs) Coesel \& Meesters 2013 & 5 & 32 \\
\hline 122 & Staurastrum bieneanum Rabenh. 1862 & 5,21 & 32, 224 \\
\hline 123 & Staurastrum bioculatum W.R.Taylor 1935 & 11 & 110 \\
\hline 124 & Staurastrum chaetoceras (Schröd.) G.M.Sm. 1924 & $\begin{array}{l}9,13,14,17,18,19, \\
20,23\end{array}$ & $\begin{array}{l}82,129,137,130,139,190,187,193,199, \\
209,247\end{array}$ \\
\hline 125 & Staurastrum cingulum (West \& G.S.West) G.M.Sm. 1922 & $\begin{array}{l}2,3,5,10,13,15,16 \\
22,24\end{array}$ & $\begin{array}{l}12,15,17,22,24,42,101,125,129,131 \\
138,145,169,175,177,182,185,245,261\end{array}$ \\
\hline 126 & Staurastrum cingulum var. obesum G.M.Sm. 1922 & 15 & 145,152 \\
\hline 127 & Staurastrum crenulatum (Nägeli) Delponte 1877 & $2,5,8,15$ & $17,35,64,151$ \\
\hline 128 & Staurastrum denticulatum (Nägeli) W.Archer 1861 & 10 & 99 \\
\hline 129 & Staurastrum furcigerum (Bréb.) W.Archer 1861 & 5,21 & $32,216,224$ \\
\hline 130 & Staurastrum gracile Ralfs ex Ralfs 1848 & $\begin{array}{l}8,14,15,16,17,19 \\
20,23\end{array}$ & $\begin{array}{l}69,140,141,148,169,186,187,189,199 \\
202,203,209,210,251\end{array}$ \\
\hline 131 & Staurastrum hexacerum Wittr. 1872 & 5 & 32,33 \\
\hline 132 & Staurastrum lapponicum (Schmidle) Grönblad 1926 & 21 & 218 \\
\hline 133 & Staurastrum manfeldtii Delponte 1878 & 5 & 32 \\
\hline 134 & Staurastrum margaritaceum Menegh. ex Ralfs 1848 & 16 & 174 \\
\hline 135 & Staurastrum muticum Bréb. ex Ralfs 1848 & 10,11 & 99, 104 \\
\hline 136 & Staurastrum muticum f. minus Rabenh. 1868* & 13 & 133 \\
\hline 137 & Staurastrum paradoxum Meyen ex Ralfs 1848 & $19,20,23$ & $201,209,254$ \\
\hline 138 & Staurastrum pilosum Bréb. 1856 & 23 & 251 \\
\hline 139 & Staurastrum pingue Teiling 1942 & $9,13,14,21,23$ & $77,127,140,219,251$ \\
\hline 140 & $\begin{array}{l}\text { Staurastrum pingue var. planctonicum (Teiling) Coesel \& } \\
\text { Meesters 2013* }\end{array}$ & 13,21 & 129, 137, 215, 219 \\
\hline 141 & Staurastrum punctulatum Bréb. 1848 & 12,25 & 120,271 \\
\hline 142 & Staurastrum striatum (West \& G.S.West) Ruzicka 1957* & 5 & 33 \\
\hline 143 & Staurastrum teliferum Ralfs $1848^{*}$ & 10 & 99 \\
\hline 144 & Staurastrum tetracerum Ralfs ex Ralfs 1848 & $\begin{array}{l}4,5,6,10,12,13 \\
16,21\end{array}$ & $\begin{array}{l}24,29,32,35,46,99,115,122,124,129 \\
131,134,137,174,175,214,216,225\end{array}$ \\
\hline 145 & Staurastrum trilobulatum Dürrschm.* & 25 & 269 \\
\hline 146 & Staurastrum vestitum Ralfs 1848 & 5 & 32 \\
\hline 147 & Staurodesmus convergens (Ehrenb. ex Ralfs) S.Lill. 1950 & 21 & 216 \\
\hline 148 & Staurodesmus dejectus (Bréb.) Teiling 1954 & 20 & 209 \\
\hline 149 & Staurodesmus dickiei (Ralfs) S.Lill. 1950 & 10,21 & 99, 216 \\
\hline 150 & Staurodesmus extensus (O.F.Andersson) Teiling 1948 & 21 & 227 \\
\hline 151 & Staurodesmus glaber (Ralfs) Teiling 1948 & 5,21 & $32,216,227$ \\
\hline 152 & Staurodesmus lobatus (Børgesen) Bourr. 1966 & 21 & 216 \\
\hline 153 & $\begin{array}{l}\text { Staurodesmus triangularis var. brevispina (V.Allorge \& } \\
\text { P.Allorge) Coesel \& Meesters 2013* }\end{array}$ & 21 & 216 \\
\hline 154 & Teilingia excavata (Ralfs ex Ralfs) Bourr. 1964 & 21 & 227 \\
\hline 155 & Teilingia granulata (J.Roy \& Bisset) Bourr. 1964 & 10,21 & 99, 216 \\
\hline 156 & $\begin{array}{l}\text { Teilingia quadrispinata f. evoluta (A.M.Scott \& Grönblad) } \\
\text { Pal.-Mordv. } 1982^{*}\end{array}$ & 5 & 32 \\
\hline 157 & Xanthidium antilopaeum Kütz. 1849 & 10 & 99 \\
\hline 158 & Zygnema pectinatum (Vaucher) Agardh 1816 & 16 & 174,180 \\
\hline
\end{tabular}

\footnotetext{
* new record for Turkish freshwaters.
} 
Phylum CHAROPHYTA

Classis Zygnematophyceae

Order Desmidiales

Family Desmidiaceae

Genus Actinotaenium (Nägeli) Teiling

Actinotaenium wollei (West \& G.S. West) Teiling 1978

(Fig. 2a)

Synonym: Cosmarium globosum var. wollei West \& G.S. West 1896

Description: Cells 27.5-47.4 $\mu \mathrm{m}$ long, 20.6-36.7 $\mu \mathrm{m}$ wide, isthmus 19.9-35.2 $\mu \mathrm{m}$. Cells 1.3-1.5 times longer than broad; cells elliptic to nearly circular, semi cells semi circular; wall finely punctate; chloroplast stellate with a central pyrenoid. The mid-region of the cell is slightly narrowed.

Ecology: This is a freshwater species.

Distribution: Europe: Austria, Britain, France, Italy, Netherlands, Spain, Ukraine; North America: Arkansas, Québec; Caribbean Islands: Cuba; South America: Brasil; South-west Asia: Bangladesh; South-east Asia: Thailand; Asia: Russia, Russia (Far East); Australia and New Zealand: New Zealand.

Occurrence: It was determined in Susurluk basin (Manyas Lake).

\section{Genus Cosmarium Corda}

Cosmarium brebissonii Menegh. 1848 (Fig. 2b)

Synonym: -

Description: Cells 45-79 $\mu \mathrm{m}$ wide, $88-110 \mu \mathrm{m}$ long. Semi cells are about trapeziform with very broadly rounded angles, walls covered with closely and evenly spaced conical granules.

Ecology: This is a freshwater species and characteristic of acidic, oligo-mesotrophic bog sites.

Distribution: Europe: Austria, Britain, Czech Republic, France, Georgia, Germany, Hungary, Ireland, Italy, Latvia, Netherlands, Portugal, Russia (Europe), Serbia, Spain, Ukraine; South America: Argentina, Brazil; Asia: China, Russia; Australia and New Zealand: Queensland.

Occurrence: It was determined in Batı Akdeniz basin (Girdev Lake).

Cosmarium contractum var. rotundatum Borge 1925 (Fig. 2c)

\section{Synonym: -}

Description: Cells 1.5-1.8 times longer than broad, small and globose, 31-52 $\mu \mathrm{m}$ long and 21-33 $\mu \mathrm{m}$ wide; semi cells are globose to subcircular that are connected by an isthmus, lateral margins of the semi cells are convex with smooth and rounded apical margin; isthmus is 3.5$5.5 \mu \mathrm{m}$ in length. Differs from the nominal variety in that semi cells are virtually circular in outline.
Ecology: This is a freshwater species.

Distribution: Europe: Austria, Britain, Czech Republic, Georgia, Germany, Netherlands; North America: Arkansas; South America: Brazil; South-east Asia: Philippines; Asia: China; Australia and New Zealand: Northern Territory.

Occurrence: It was determined in Kiz1lırmak basin (Küçük Lota Lake).

Cosmarium distentum (West) Coesel \& Meesters 2015 (Fig. 2d)

Synonym: Cosmarium laeve var. distentum G.S. West

Description: Cells 14-18 $\mu \mathrm{m}$ long, 11-15 $\mu \mathrm{m}$ wide, isthmus 3-4 $\mu \mathrm{m}$. Cell length to breadth ratio is lower from the described diagnosis of Cosmarium laeve Rabenh. Semi cells widely ovate from the broad base, apex rounded or slightly truncate, a prominent tubercle in the center of the semi cell. The cell wall is finely punctate.

Ecology: This is a freshwater species.

Distribution: Europe: Netherlands.

Occurrence: It was determined in Batı Akdeniz (Girdev Lake) and Sakarya basins (Poyrazlar Lake).

Cosmarium humile var. substriatum (Nordst.) Schmidle 1895 (Fig. 2e)

Synonym: -

Description: Cells 17-28 $\mu \mathrm{m}$ long, 16-26 $\mu \mathrm{m}$ wide. The cell wall is sculptured by both incurvations and granules. Differs from the nominate variety by larger cell dimensions and in that the granules are arranged in two intramarginal series.

Ecology: This is a freshwater species and rather common species in various kinds of circumneutral, mesoeutrophic water bodies.

Distribution: Europe: Britain, Germany, Ireland, Italy, Latvia, Netherlands, Serbia, Slovenia, Ukraine; North America: Québec; South America: Argentina; South-west Asia: India; Asia: Russia, Tajikistan.

Occurrence: It was determined in Bat1 Akdeniz basin (Avlan Lake).

Cosmarium impressulum var. crenulatum (Nägeli) Willi Krieg. \& Gerloff 1965 (Fig. 2f)

Synonym: Cosmarium crenulatum Nägeli

Description: Cells 29-33 $\mu \mathrm{m}$ long, 20-24 $\mu \mathrm{m}$ wide. Cells longer than broad, in rough outline oval with regularly undulate margin. Half-cells transverse hexagonal. In the apical view elliptical, in the lateral view broadly oval. Cell wall smooth.

Ecology: This is a freshwater species and prefers mesotrophic water. 
Distribution: Europe: Austria, Britain, Netherlands, Serbia; South America: Argentina; South-west Asia: India; South-east Asia: Thailand.

Occurrence: It was determined in Kizılirmak basin (Palanga Lake).

Cosmarium mamilliferum var. madagascariense West \& G.S. West 1895 (Fig. 2g)

\section{Synonym: -}

Description: Cells 32-43 $\mu \mathrm{m}$ long, 25-36 $\mu \mathrm{m}$ wide, isthmus $7 \mu \mathrm{m}$, elliptical apical view, the wall is strongly scrobiculate.

Ecology: No habitat entry has yet been made for this entity.

Distribution: Africa: Zimbabwe.

Occurrence: It was determined in Frrat-Dicle basin (Hazar Lake).

Cosmarium nymannianum Grunov 1866 (Fig. 2h)

Synonym: -

Description: Cells 30-54 $\mu \mathrm{m}$ long and 29-42 $\mu \mathrm{m}$ wide; isthmus 12-13 $\mu \mathrm{m}$ wide; subhexagonal, elongate, sinus narrow, linear, semi cells are trapeziform in outline with concave lateral sides and apex, truncate-pyramidal with rounded basal and upper angles.

Ecology: This is a freshwater species.

Distribution: Europe: Austria, Britain, France, Germany, Ireland, Italy, Latvia, Spain, Ukraine; North America: Florida, Newfoundland, Québec; South America: Brazil; South-west Asia: India, Pakistan; Asia: Japan, Russia.

Occurrence: It was determined in Antalya basin (Düden Lake).

Cosmarium pseudowembaerense Kouwets 1998 (Fig. 2i)

Synonym: -

Description: Cells $12-18 \mu \mathrm{m}$ long, $10-17 \mu \mathrm{m}$ wide. Cells about as long as broad or a little longer, with a deep, linear sinus, closed for the greater part. Semi cells about hexagonal with broadly rounded angles and straight to slightly concave lateral sides, oval-elliptic in apical view. Apex is distinctly concave. Cell wall is smooth.

Ecology: This is a freshwater species.

Distribution: Europe: Czech Republic, France, Germany, Netherlands; South America: Brazil.

Occurrence: It was determined in Batı Akdeniz (Avlan Lake) and Firat-Dicle basins (Kalecik Reservoir).

Cosmarium quinarium Lundell 1871 (Fig. 2j)

Synonym: -
Description: Cells 30-39 $\mu \mathrm{m}$ wide, 36-48 $\mu \mathrm{m}$ long, sinus deep, narrow, linear. Trapeziform semi cells with broadly rounded angles and slightly convex sides being marked with distant granules.

Ecology: This is a freshwater species.

Distribution: Europe: Austria, Britain, France, Germany, Ireland, Latvia, Netherlands, Scandinavia, Slovakia, Sweden, Ukraine; North America: Florida, Québec; South America: Brazil; South-west Asia: Bangladesh, India, Pakistan; South-east Asia: Thailand; Asia: Japan, Russia, Russia (Far East), Taiwan.

Occurrence: It was determined in Sakarya basin (Avdan Lake).

\section{Cosmarium sphagnicola West \& West 1897 (Fig. 2k)}

\section{Synonym: -}

Description: Cells 9-13 $\mu \mathrm{m}$ long, 10-14 $\mu \mathrm{m}$ wide. Cells very small, roughly as long as they are wide. Halfcells elongated hexagonal with rounded corners and abroad, flat or slightly concave apex. Apical views elliptical, half-cells in a lateral view broadly oval or almost circular.

Ecology: This is a freshwater species.

Distribution: Europe: Austria, Britain, Czech Republic, France, Germany, Hungary, Ireland, Italy, Latvia, Netherlands, Portugal, Romania, Scandinavia, Spain, Ukraine; North America: Québec; South America: Brazil; Asia: Russia, Russia (Far East); Australia and New Zealand: New Zealand.

Occurrence: It has been detected in the Batı Akdeniz basin (Girdev Lake).

Cosmarium subadoxum Grönblad 2007 (Fig. 21)

Synonym: -

Description: Cell 8-11 $\mu \mathrm{m}$ long, 8-11 $\mu \mathrm{m}$ wide. Cells about as long as broad with a deep, linear sinus, closed for the greater part. Semi cells in outline rectangular with convex lateral sides. Semi cells in apical view elliptic with a small, median tubercle on either side.

Ecology: This is a freshwater species.

Distribution: Europe: Czech Republic, France, Netherlands; South America: Brazil.

Occurrence: It was determined in Sakarya (Poyrazlar Lake), Frrat-Dicle (Kapıaçmaz Pond, Hasancık Pond), and Asi basins (Yarseli Reservoir, Üçpınar Pond).

Cosmarium subgranatum (Nordst.) Lütkem. 1902 (Fig. 2m)

\section{Synonym: -}

Description: Cells 20-34 $\mu \mathrm{m}$ long, 15-25 $\mu \mathrm{m}$ wide. Cells longer than broad with a deep, linear sinus, closed for the greater part. Semi cells in rough outline pyramidal with lateral sides and undulations of the magrin are pretty 
irregular. Apical view ellipsoid with median inflation. Cell wall smooth.

Ecology: This is a freshwater species and common in meso-eutrophic water bodies, both acidic and alkaline.

Distribution: Arctic: Ellesmere Island; Europe: Britain, Czech Republic, France, Georgia, Germany, Hungary, Ireland, Italy, Netherlands, Romania, Serbia, Slovakia, Slovenia, Ukraine; North America: Northwest Territories, Québec; Caribbean Islands: Cuba; South America: Brazil; Middle East: Iraq; Asia: Myanmar; Asia: China, Russia (Far East), Taiwan, Tajikistan; Australia and New Zealand: New Zealand; Pacific Islands: Hawaiian Islands.

Occurrence: It was determined in Sakarya basin (Avdan Lake).

\section{Cosmarium subquadrans West \& West 1905 (Fig. 2n) \\ Synonym: -}

Description: Cells small, 11-12.5 $\mu \mathrm{m}$ long, $12-15 \mu \mathrm{m}$ wide, isthmus 3.5-4 $\mu \mathrm{m}$ wide, semi cells in front view transversely oblong, apex broad, truncate or slightly convex, semi cells in lateral view subcircular; vertical view fusiform-elliptic; cell wall smooth.

Ecology: This is a freshwater species.

Distribution: Europe: Austria, Britain, Czech Republic, Germany, Ireland, Italy, Netherlands, Ukraine; Asia: China, Japan, Russia, Tajikistan.

Occurrence: It was determined in Asi basin (Yarseli Reservoir, Üçpınar Pond).

Cosmarium subquadrans var. minus Symoens 1873 (Fig. 20)

\section{Synonym: -}

Description: Cells $12-13 \mu \mathrm{m}$ long, $16-18 \mu \mathrm{m}$ wide. Cells broader than long, in outline oval with a deep, linear sinus, closed for the greater part. Semi cells entire with broadly rounded angles, in apical view fusiform to rhomboid. Cell wall smooth.

Ecology: This is a freshwater species.

Distribution: Europe: Czech Republic, Germany, Ireland, Netherlands.

Occurrence: It was determined in Sakarya basin (Sapanca Lake).

\section{Cosmarium tetrachondrum Lundell 1871 (Fig. 2p)}

\section{Synonym: -}

Description: Cell 20-23 $\mu \mathrm{m}$ long, 23-27 $\mu \mathrm{m}$ wide. Cells broader than long with a deep, linear sinus, closed for the greater part. Semi cells in outline low-trapeziform with broadly rounded angles. Apical view ellipsoid.

Ecology: This is a freshwater species.
Distribution: Europe: Britain, Czech Republic, France, Germany, Ireland, Latvia, Netherlands, Ukraine. Asia: Japan, Russia.

Occurrence: It was determined in Batı Akdeniz basin (Girdev Lake).

$$
\text { Genus Desmidium C. Agardh }
$$

Desmidium aptogonum Bréb. 1849 (Fig. 3a)

\section{Synonym: -}

Description: Cells 21-31 $\mu \mathrm{m}$ wide, 13-19 $\mu \mathrm{m}$ long, moderately constricted with an acute, open sinus; isthmus 15-24.5 $\mu \mathrm{m}$ wide; semi cells transversely oblong, lateral margins are slightly concave then converging to the apex.

Ecology: This is a freshwater species.

Distribution: Europe: Britain, Czech Republic, Finland, France, Georgia, Germany, Ireland, Italy, Netherlands, Portugal, Scandinavia, Slovenia, Spain, Sweden, Ukraine; North America: Florida, Maryland, New York, Québec, Wisconsin; Caribbean Islands: Cuba; South America: Brazil, Uruguay; Middle East: Iraq; South-west Asia: Bangladesh; India, Pakistan; South-east Asia: Myanmar, Thailand; Asia: China, Japan, Russia (Far East), Tajikistan; Australia and New Zealand: New South Wales, New Zealand, Northern Territory, Queensland, Victoria; Pacific Islands: Hawaiian Islands.

Occurrence: It was determined in Büyük Menderes basin (Karakuyu Reeds).

\section{Genus Euastrum Ehrenb.}

Euastrum lacustre (Messik.) Coesel 1984 (Fig. 3b)

\section{Synonym: -}

Description: Cells 28-48 $\mu \mathrm{m}$ long, 26-46 $\mu \mathrm{m}$ wide, isthmus 9-10 $\mu \mathrm{m}$ wide. Cells medium-sized, sinus narrow linear with dilated apex, semi cells nearly quadrangular, cell wall smooth.

Ecology: This is a freshwater species.

Distribution: Europe: Britain, France, Netherlands.

Occurrence: It was determined in Kizılırmak basin (Hafik Lake).

\section{Genus Groenbladia Teiling}

Groenbladia undulata (Nordst.) Kurt Först. 1973 (Fig. 3c)

Synonym: Hyalotheca undulata Nordst.

Description: Cells 10-17.5 $\mu \mathrm{m}$ long, 6-9 $\mu \mathrm{m}$ wide, more or less dumbbell-shaped, shallow median indentation; isthmus 4.5-7.5 $\mu \mathrm{m}$ wide, filaments sometimes in a mucilage sheath.

Ecology: This is a freshwater species.

Distribution: Europe: Austria, Britain, France, Germany, Ireland, Scandinavia, Spain; North America: Arkansas, Maine, Québec; Caribbean Islands: Cuba; 
South America: Brazil; South-west Asia: Bangladesh; Australia and New Zealand: Northern Territory.

Occurrence: It was determined in Sakarya basin (Akgöl 1 Lake).

Genus Micrasterias Agardh

Micrasterias furcata Agardh 1848 (Fig. 3d)

\section{Synonym: -}

Description: Cells $150 \mu \mathrm{m}$ long, $130 \mu \mathrm{m}$ wide, isthmus 17-20 $\mu \mathrm{m}$ wide, cells are elliptical in outline with narrowly opened deep sinus. Semi cells with welldeveloped lateral lobes. The cell wall is smooth.

Ecology: This is a freshwater species.

Distribution: Europe: Austria, Britain, Czech Republic, France, Germany, Ireland, Italy, Netherlands, Romania, Spain, Ukraine; North America: Arkansas, Maine, Québec, Wisconsin; Caribbean Islands: Cuba; South America: Brazil, Uruguay; Middle East: Iraq; Asia: Russia (Far East); Australia and New Zealand: Victoria.

Occurrence: It was determined in Sakarya basin (Işık Dağ̀ Karagöl Lake).

Genus Spondylosium Bréb.

Spondylosium panduriforme (Heimerl) Teiling 1957 (Fig. 3e)

Synonym: Cosmarium moniliforme var. panduriforme (Heimerl) Schmidle

Description: Cells 36-42 $\mu \mathrm{m}$ long, 21-22 $\mu \mathrm{m}$ broad, isthmus 13.2-14 $\mu \mathrm{m}$. Semi cells circular; apex broadly rounded; cell wall finely punctate. This species is characterized by a copious mucilaginous envelope, enclosing the complete cell body.

Ecology: This is a freshwater species.

Distribution: Europe: France, Germany, Ireland, Italy, Netherlands, Ukraine; South America: Argentina, Brazil, Uruguay; South-west Asia: Bangladesh; Asia: Russia (Far East); Australia and New Zealand: New South Wales, New Zealand.

Occurence: It was determined in the Frrat-Dicle basin (Kapıaçmaz Pond).

\section{Genus Staurastrum Meyen}

Staurastrum pingue var. planctonicum (Teiling) Coesel \& Meersters 2013 (Fig. 3f)

Synonym: Staurastrum planctonicum Teiling

Description: Cells 3 radiate, 70-95 $\mu \mathrm{m}$ wide, 57-65 $\mu \mathrm{m}$ long with processes, isthmus $9-13 \mu \mathrm{m}$ wide; lower part of semi cells elongate, cup-shaped flaring upwards into long, slightly divergent, curved processes, walls smooth.

Ecology: This is a freshwater species.
Distribution: Europe: Bulgaria; Africa: Democratic Republic of Congo.

Occurrence: It was determined in Sakarya (Sapanca Lake, Üçlerkayası Pond) and Frrat-Dicle basins (Palandöken Pond, Otlukbeli Pond).

Staurastrum muticum f. minus Rabenh. 1868 (Fig. 3g)

Synonym: -

Description: Cells 21-22 $\mu \mathrm{m}$ long, 19-21 $\mu \mathrm{m}$ wide, isthmus 7-8 $\mu \mathrm{m}$. Cells medium-sized, very slightly longer than broad, semi cells narrowly elliptic oval, in vertical view cells triangular, narrowly rounded at the angles, cell wall finely and densely punctate.

Ecology: This is a freshwater species.

Distribution: Europe: Ireland, Netherlands; North America: Québec; South America: Argentina; South-west Asia: India; Australia and New Zealand: Northern Territory.

Occurrence: It was determined in Firat-Dicle basin (Dedeyolu Pond).

\section{Staurastrum striatum (West \& West) Ruzicka 1957} (Fig. 3h)

\section{Synonym: -}

Description: Cells 25-35 $\mu \mathrm{m}$ long, 24-36 $\mu \mathrm{m}$ wide. Cells about as long as broad, deeply constricted. Sinus is widely open, acute-angled. Semi cells (sub) rhomboid with rounded, or rounded-truncate lateral angles. Semi cells in apical view 3 -angular with slightly concave sides and rounded, or rounded-truncate angles.

Ecology: This is a freshwater species.

Distribution: Europe: Czech Republic, France, Germany, Netherlands, Romania, Serbia; Australia and New Zealand: New South Wales.

Occurrence: It was determined in Batı Akdeniz basin (Avlan Lake).

\section{Staurastrum teliferum Ralfs 1848 (Fig. 3i)}

\section{Synonym: -}

Description: Cells 3-radiate, 40-64 $\mu \mathrm{m}$ wide, 32-56 $\mu \mathrm{m}$ long excluding spines, deeply constricted with an open sinus, isthmus 8-10 $\mu \mathrm{m}$ wide; semi cells elliptical with broadly rounded angles.

Ecology: This is a freshwater species.

Distribution: Europe: Andorra, Austria, Baltic Sea, Britain, Czech Republic, France, Georgia, Germany, Hungary, Ireland, Italy, Latvia, Netherlands, Portugal, Romania, Scandinavia, Serbia, Slovakia, Slovenia, Spain, Ukraine; North America: Northwest Territories, Québec; South America: Brazil, Uruguay; Africa: Zaire; Middle East: Iraq; South-west Asia: India; Asia: China, Japan, Taiwan. 
Occurrence: It was determined in Çoruh basin (Çil Lake).

\section{Staurastrum trilobulatum Dürrschm. (Fig. 3j)}

\section{Synonym: -}

Description: Cells 1.1-1.4 times longer than wide, 13$26 \mu \mathrm{m}$ wide, 18-31 $\mu \mathrm{m}$ long, isthmus 5-8 $\mu \mathrm{m}$; median constriction deep, sinus closed; semi cells subtrapezoidal and 3-lobed, with truncate basal lobes and apex, rectangular basal angles and apical slightly rounded; semi cells elliptic in apical and lateral view, cell wall smooth or finely punctate.

Ecology: This is a freshwater species.

Distribution: No record was found regarding the distribution range of this taxon.

Occurrence: It was determined in Yeşilırmak basin (Uyuz Lake).

\section{Genus Staurodesmus Teiling}

Staurodesmus triangularis var. brevispina (Allorge \& Allorge) Coesel \& Meesters 2013 (Fig. 3k)

\section{Synonym: -}

Description: Cells mostly biradiate, rarely triradiate, 19-25 $\mu \mathrm{m}$ long, 19-25 $\mu \mathrm{m}$ wide (excluding spines). Isthmus short, 5-7 $\mu \mathrm{m}$ wide. This species is characterized by biradiate cells, relatively short spines, and 'elevated' apices. Spinesshorter than $2 / 3$ breadth of the semi cell body. Lateral sides of semi cell body straight to slightly convex.

Ecology: This is a freshwater species.

Distribution: No record was found regarding the distribution range of this taxon.

Occurrence: It was determined in Sakarya basin (Işık Dağı Karagöl Lake).

\section{Genus Teilingia Bourr.}

Species: Teilingia quadrispinata f. evoluta (A.M.Scott \& Grönblad) Pal.-Mordv. (Fig. 3m)

Synonym: Sphaerozosma quadrispinatum f. evolutum A.M.Scott \& Grönblad

Description: Cells 7.5-10.7 $\mu \mathrm{mlong}, 8.7-11.5 \mu \mathrm{m}$ wide, istmus 4.1-5.7 $\mu \mathrm{m}$.

Ecology: This is a freshwater species.

Distribution: North America: Florida, Asia: Russia.

Occurrence: It was determined in Batı Akdeniz basin (Girdev Lake).

\section{Family Closteriaceae \\ Genus Closterium Nitzsch}

Closterium dianae var. rectius (Norst.) De Toni 1977 (Fig. 3n)

\section{Synonym: -}

Description: Cells 150-380 $\mu \mathrm{m}$ long, 8-16 $\mu \mathrm{m}$ wide. Cells approximately 8-15 times as long as wide, evenly slightly to strongly curved, cell wall always smooth, without girdles.

Ecology: This is a freshwater species.

Distribution: Europe: Czech Republic, Germany, Netherlands.

Occurrence: It was determined in Akarçay basin (Eber Lake).

Closterium pygmaeum Gutw. 1890 (Fig. 3o)

\section{Synonym: -}

Description: Cells $57 \mu \mathrm{m}$ long and $5.3 \mu \mathrm{m}$ wide, slightly curved, gradually attenuated toward the apex which is rounded; cell wall smooth, cells contain two pyrenoids in half part of the cell.

Ecology: This is a freshwater species.

Distribution: Europe: Austria, Britain, France, Germany, Netherlands, Scandinavia, Spain, Ukraine; South America: Brazil; Australia and New Zealand: New South Wales, Tasmania.

Occurrence: It was determined in Sakarya basin (Avdan Lake).

$$
\begin{gathered}
\text { Order Zygnematales } \\
\text { Family Zygnemataceae } \\
\text { Genus Spirogyra Link }
\end{gathered}
$$

Spirogyra decimina var. elongata (Vaucher) Petlovany 2015 (Fig. 31)

Synonym: Spirogyra elongata (Vaucher) Dumortier

Description: Cells 45-280 $\mu \mathrm{m}$ long, 26-38 $\mu \mathrm{m}$ wide, chloroplast single, making 2-5 turns of cell; conjugation ladder-like and lateral, conjugation scalariform; median wall smooth, thick with a wavy suture line.

Ecology: This is a freshwater species.

Distribution: Europe: Britain, Georgia, Germany, Ireland; Latvia, Netherlands, Romania, Russia (Europe), Slovakia, Slovenia, Spain; North America: California, Laurentian Great Lakes, Québec; South America: Argentina, Brazil; Middle East: Iraq, Turkey; South-west Asia: India, Asia: China, Japan, Tajikistan; Australia and New Zealand: New South Wales, New Zealand, Queensland, South Australia.

Occurrence: It was determined in Antalya basin (Eğirdir Lake).

\section{Discussion}

A total of 158 taxa from Charophyta were determined in the study conducted from 2017 to 2019 in 25 river basins of Turkey. Of these 31 taxa represent new records for the freshwater algal flora of Turkey. They belong to genera Cosmarium (15), Staurastrum (5), Closterium (2), Actinotaenium (1), Desmidium (1), Eastrum (1), 
Groenbladia (1), Micrasterias (1), Spirogyra (1), Spondylosium (1), Staurodesmus (1), and Teilingia (1).

Although some of the Charophyta taxa (Elakatothrix gelatinosa, Staurastrum tetracerum, Cosmarium laeve, Staurastrum cingulum, Closterium aciculare, Staurastrum gracile, Cosmarium neodepressum, Staurastrum chaetoceras, Closterium acutum var. variabile, Closterium littorale) found to have a wide distribution in 25 river basins of Turkey, most of the charophyta taxa (115 taxa) found to have rare distribution and were only observed in 1 or 2 lakes in 25 river basins. Besides, all of 31 new records have a rare distribution range except Cosmarium subadoxum and Staurastrum pingue var. Planctonicum. Elakatothrix gelatinosa has the highest distribution rate with its occurrence in 29 lakes, among the member of Charophyta.

There is no direct correlation between the number of lakes sampled in the basins and the number of species found. Despite sampling 23 lakes in Kizılırmak basin, only 15 Charophyta taxa were found in Kizılırmak basin, and only 6 Charophyta taxa were found in Ceyhan basin despite 18 sampling lakes. However, 42 Charophyta taxa were found in Batı Akdeniz where only 13 lakes were studied and 27 Charophyta taxa were found in Antalya basin where only 9 lakes were studied.

Basin-based distributions of Charophyta members identified in this study were as below: 50 taxa in Sakarya, 42 in Batı Akdeniz, 27 in Antalya, 26 in Konya, 21 in Firat-Dicle, 17 in Çoruh, 15 in Kizılırmak, 13 in Yeşilırmak, Susurluk, Asi, 12 in Meriç Ergene, 10 in Kuzey Ege, 9 in Gediz, Akarçay, Büyük Menderes, 6 in Ceyhan, Doğu Akdeniz, 4 in Seyhan, Küçük Menderes, and 3 in Batı Karadeniz, Doğu Karadeniz, Marmara, Van Gölü, Aras basins. The Burdur basin is the only basin that no Charophyta species were found. The reason for this is that high salinity in Acs Lake, high $\mathrm{pH}$ in Salda Lake and higher eutrophic features in Burdur and Karataş Lakes. Thus, Desmids, which are sensitive species, were not found in the lakes of Burdur basin. The highest Charophyta diversity was observed in Girdev Lake (Batı Akdeniz basin) and Işık Dağı Karagöl Lake (Sakarya basin) among the lakes of Turkey's 25 river basins in this study. The moderate ecological status in both lakes proves that desmids are mostly appear in uncontaminated waters.

Charophytes are commonly found in freshwater habitats such as ponds and streams, and few species are found in brackish waters (Adl et al. 2005). Most of the species are known from the temperate zone, but they also tolerate polar conditions (Gąbka 2007, Boszke \& Bociąg 2008). Desmidales, as an important ordo in Charophyta, are mostly planktonic organisms that very sensitive to environmental changes, and eutrophic conditions do not contain ideal growth conditions for these group members (Davis 1955, Edmondson 1959, Gayathri et al. 2011). They occur typically in clean standing waters such as lakes, ponds or shallow pools. The highest diversity is found in mesotrophic, slightly acidic to slightly alkaline water bodies like fen hollows or moorland pools where desmids are among the dominant groups of the phytobenthos, both in terms of species richness and biomass (Coesel \& Meesters 2007). Desmids are not merely one of the main freshwater microalgae groups that occur in high mountain lakes biotopes in Turkey, but they also inhabit microhabitats with oligotrophic conditions characterized by relatively acidic to weakly alkaline waters with low conductivity (Şahin \& Akar 2019). In this study, only the Spirogyra decimina var. elongata was identified from the Zygnematales order. Spirogyra species were found in freshwater habitats under moderately eutrophic or mesotrophic conditions (Novis 2004, Stancheva et al. 2013, Sherwood et al. 2018). They mostly occurr in benthos (Volkova et al. 2018) but they can also be found in plankton (Kravtsova et al. 2020).

In conclusion, 31 new records were added to the freshwater algal flora of Turkey within this study. 13 of these newly recorded taxa belong to the Charophyta group, which are widely distributed in different parts of the world and 18 taxa are rarely distributed. When the current new records of this study were added to the previous Turkish algae list of Taşkın et al. (2019) and the database of Turkish algae (Maraşlığlu \& Gönülol 2021) which is formed by screening a large number of studies on Turkish algae, it can be concluded that there is nearly around 450 Charophyta species in Turkish freshwaters. 

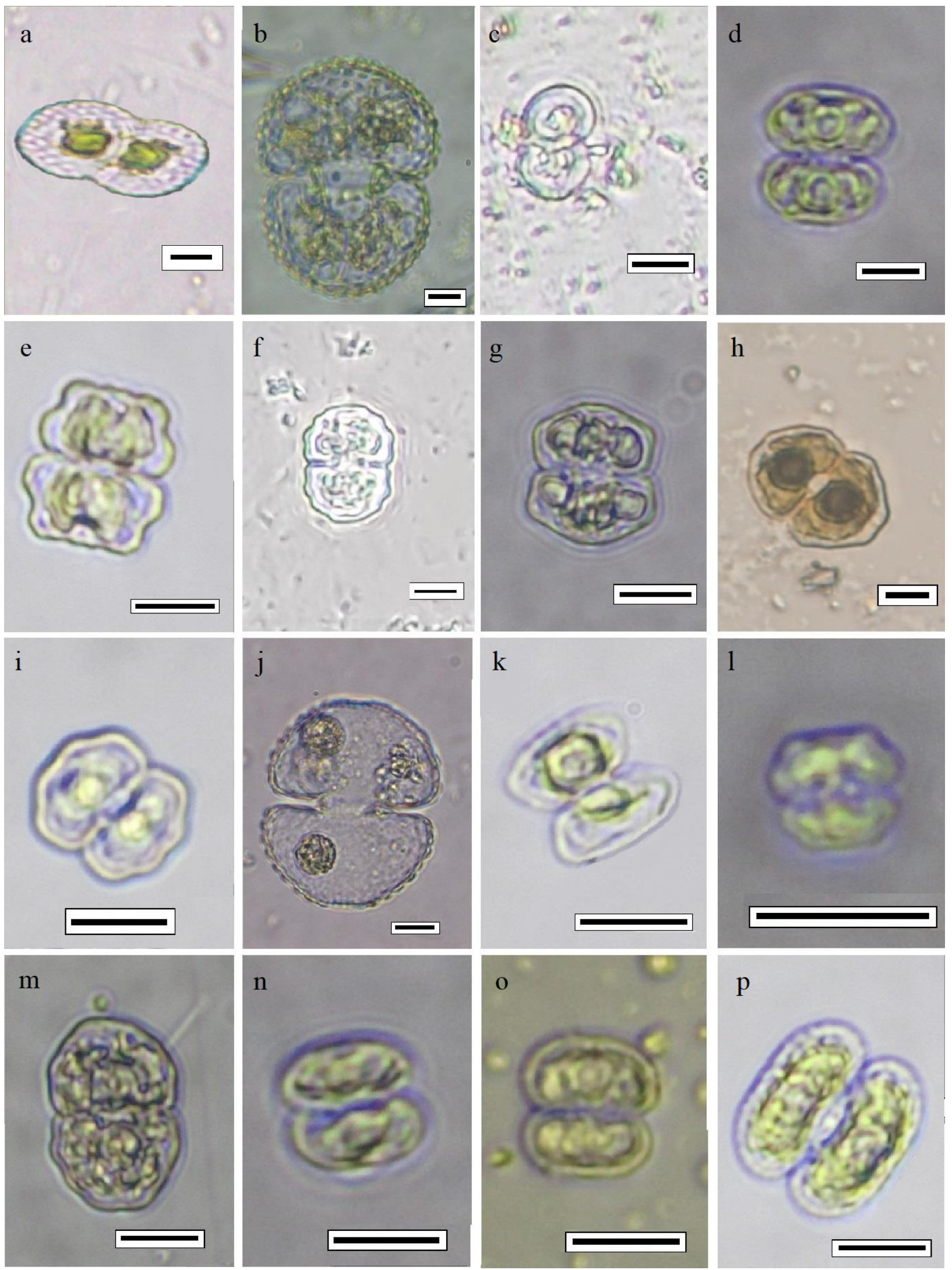

Fig. 2. Microscopic view of determined Desmidiales species; a) Actinotaenium wollei, b) Cosmarium brebissonii, c) Cosmarium contractum var. rotundatum, d) Cosmarium distentum, e) Cosmarium humile var. substriatum, f) Cosmarium impressulum var. crenulatum, $\mathbf{g}$ ) Cosmarium mamilliferum var. madagascariense, $\mathbf{h}$ ) Cosmarium nymannianum, i) Cosmarium pseudowembaerense, $\mathbf{j}$ ) Cosmarium quinarium, k) Cosmarium sphagnicola, l) Cosmarium subadoxum, m) Cosmarium subgranatum, n) Cosmarium subquadrans, o) Cosmarium subquadrans var. minus, p) Cosmarium tetrachondrum. Scales $10 \mu \mathrm{m}$. 

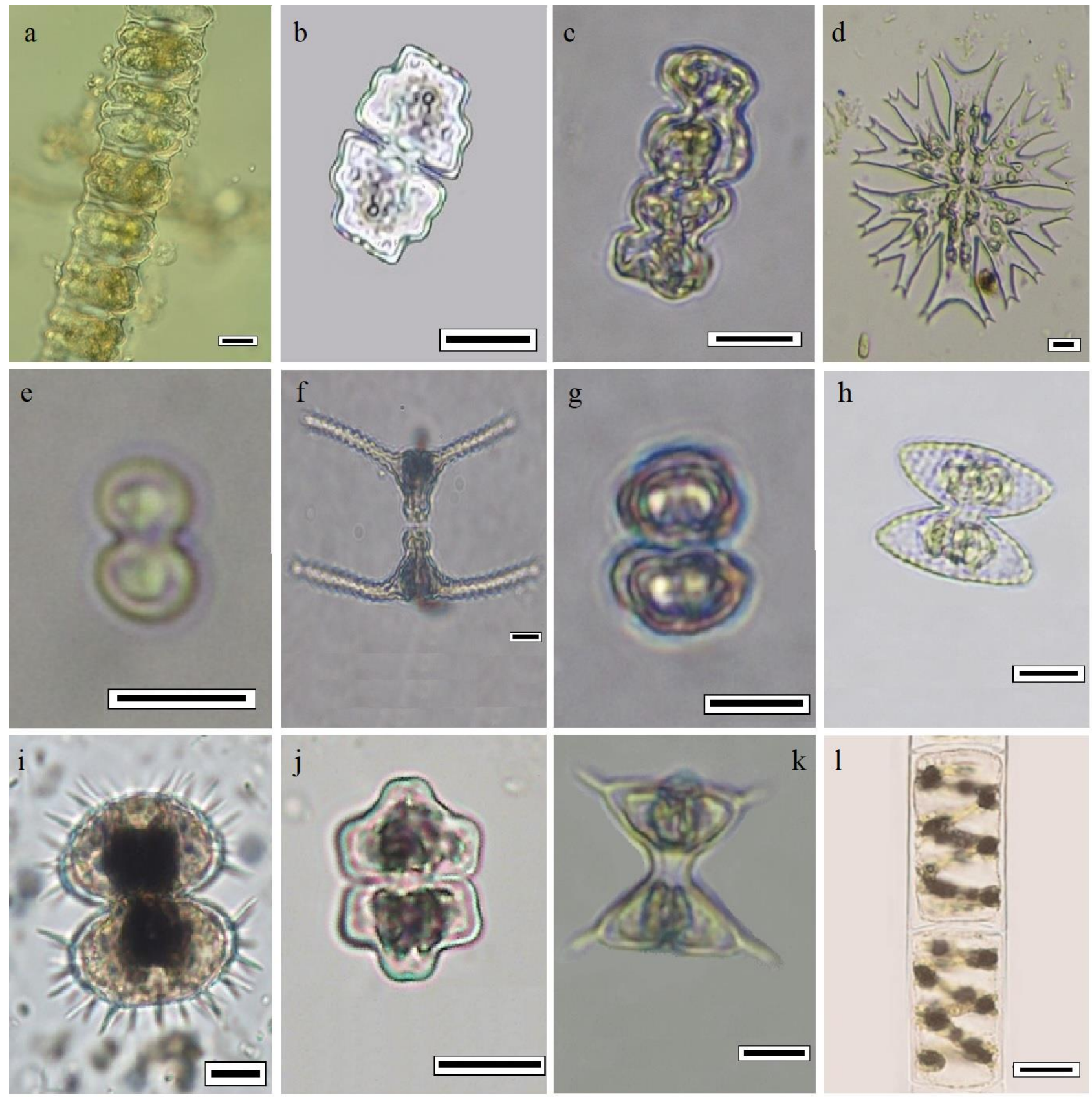

h
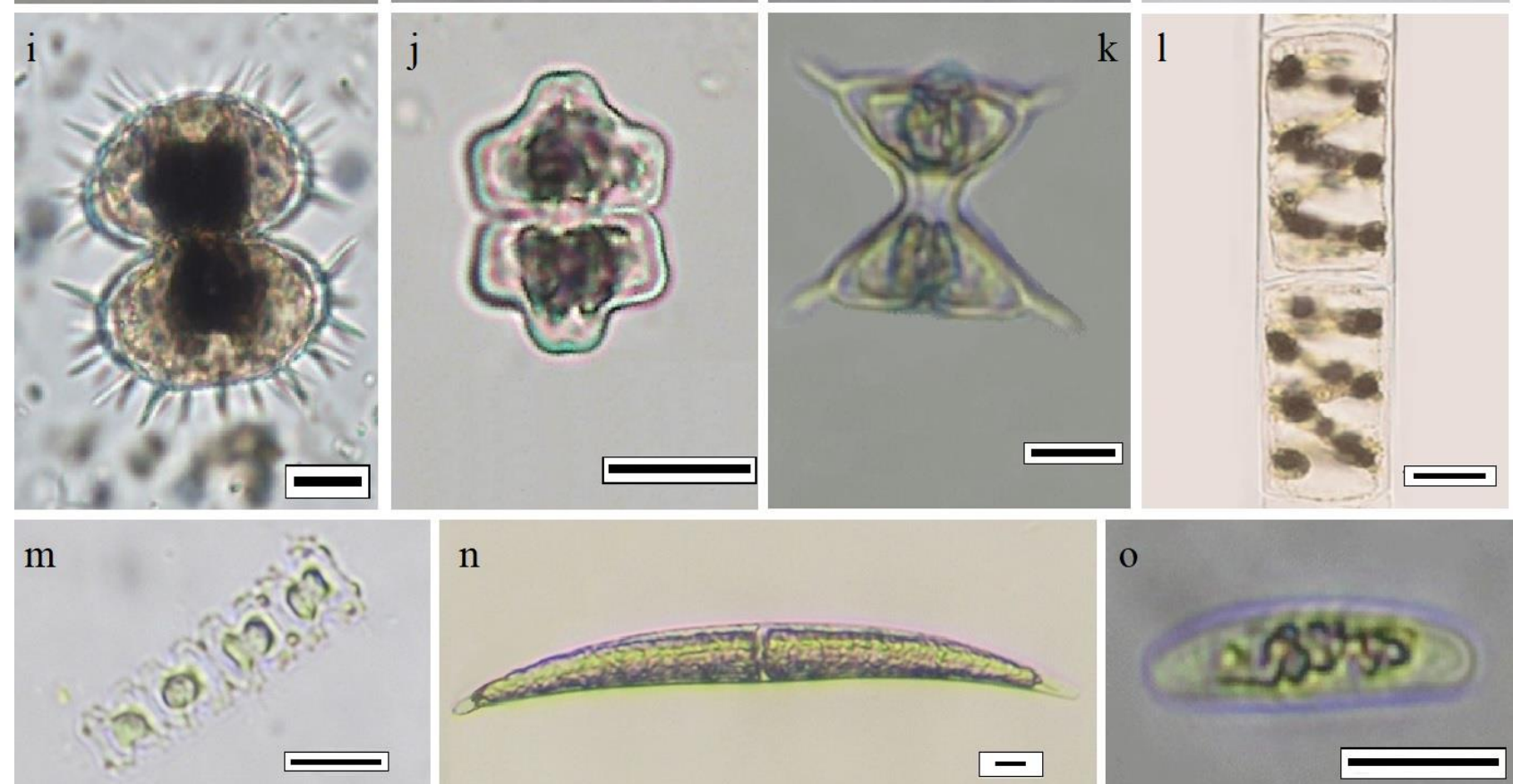

Fig. 3. Microscopic wiew of determined Desmidiales and Zygnematales species; a) Desmidium aptogonum, b) Euastrum lacustre, c) Groenbladia undulata, d) Micrasterias furcata, e) Spondylosium panduriforme, f) Staurastrum pingue var. planctonicum, g) Staurastrum muticum f. minus, h) Staurastrum striatum, i) Staurastrum teliferum, j) Staurastrum trilobulatum, k) Staurodesmus triangularis var. brevispina, l) Spirogyra decimina var. elongata m) Teilingia quadrispinata f. evoluta, n) Closterium dianae var. rectius, o) Closterium pygmaeum. Scales $10 \mu \mathrm{m}$. 


\section{Acknowledgement}

We would like to thank the executives and the staff of Çınar Engineering Consulting Co. (Turkey) who had executed the Project (Establishment of Reference Monitoring Network in Turkey, 2017-2019).

Ethics Committee Approval: Since the article does not contain any studies with human or animal subject, its approval to the ethics committee was not required.

Author Contributions: Concept: F.M., T.O.S., Desing: F.M., E.N.S., T.O.S., Execution: F.M., E.N.S., N.D., A.Ç., H.S., B.Ö., T.O.S., B.T., Material supplying: F.M., E.N.S., N.D., A.Ç., H.S., B.Ö., T.O.S., T.C., C.N.S., B.T., Data acquisition: F.M., E.N.S., N.D., A.Ç., H.S., B.Ö., T.O.S., T.C., C.N.S., B.T., Data

\section{References}

1. Adl, S.M., Simpson A.G.B., Farmer, M.A, Andersen, R.A., Anderson, O.R., Barta, J.R., Bowser, S.S., Brugerolle, G., Fensome, R.A., Fredericq, S., James, T.Y., Karpov, S., Kugrens, P., Krug, J., Lane, C.E., Lewis, L.A., Lodge, J., Lynn, D.H., Mann, D.G., McCourt, R.M., Mendoza, L., Moestrup, O., Mozley-Standridge, S.E., Nerad, T.A., Shearer, C.A., Smirnov, A.V., Spiegel, F.W. \& Taylor M.F.H.R. 2005. The new higher level classification of eukaryotes with emphasis on the taxonomy of protists. The Journal of Eukaryotic Microbiology, 52(5): 399-451. https://doi.org/10.1111/j.1550-7408.2005.00053.x

2. Akar, B. \& Şahin, B. 2014. New desmid records of Karagö1 Lake in Karagöl-Sahara National Park (ŞavşatArtvin/Turkey). Turkish Journal of Fisheries and Aquatic Sciences, 14(1): 269-274. https://doi.org/10.4194/13032712-v14_1_29

3. Apaydın-Yağcı, M. \& Turna, İ.İ. 2002. A new record for the algal flora of Turkey: Chaetomorpha crassa (C.ag.) Kütz. (Cladophoraceae, Chlorophyceae). Turkish Journal of Botany, 26: 171-174.

4. Atıc1, T. 2002. Nineteen new records from Sariyar Dam Reservoir phytoplankton for Turkish Freshwater algae. Turkish Journal of Botany, 26(6): 485-490.

5. Aysel, V. 2005. Check-List of the Freshwater Algae of Turkey. Journal of Black Sea/Mediterranean Environment, 11: $1-124$.

6. Aysel, V., Dural, B., \& Gezerler-Şipal, U. 1993. Two new records of Cyanophyceae for the Algal Flora of Turkey. Turkish Journal of Botany, 17: 263-266.

7. Baykal, T., Akbulut, T., Açıkgöz, İ., Udoh, A.U., Yıldız, K. \& Şen, B. 2009. New Records For the Freshwater Algae of Turkey. Turkish Journal of Botany, 33: 141-152.

8. Bekleyen, A., Gokot, B. \& Varol, M. 2011. Thirty-four new records and the diversity of the Rotifera in the Turkish part of the Tigris River watershed, with remarks on biogeographically interesting taxa. Scientific Research and Essays, 6(30): 6270-6284. https://doi.org/10.5897/ $\underline{\text { SRE11.355 }}$

9. Boszke, P. \& Bociag, K. 2008. Morphological ، variation of oospores in the population of Chara rudis A. Braun in a mesotrophic lake. Polish Journal of Ecology, 56(1): 139147. analysis/interpretation: F.M., E.N.S., A.Ç., H.S., B.Ö., T.O.S., B.T., Writing: F.M., E.N.S., T.O.S., Critical review: F.M., T.O.S., T.C., Y.K.

Conflict of Interest: The authors have no conflicts of interest to declare.

Funding: This study was supported by the Ministry of Agriculture and Forestry, Directorate General of Water Management (Project number: 2011K050400).

Editor-in-Chief note: Burak Öterler and Tuğba Ongun Sevindik are members of Trakya University Journal of Natural Sciences Editorial Board. However, they weren't involved in the decision process during manuscript evaluation.

10. Brummitt, R.K. \& Powell, C.E. 1992. Authors of Plant Names. A List of Authors of Scientific Names of Plants, With Recommended Standard Forms of Their Names, Including Abbreviations. Royal Botanic Gardens, Kew, $732 \mathrm{pp}$.

11. Coesel, P.F.M. \& Meesters, K.J. 2007. Desmids of the lowlands: Mesotaeniaceae and Desmidiaceae of the European lowlands. Zeist, NLD, KNNV Publishing, 351 pp.

12. Coesel, P.F.M. 1998. Sieralgen en Natuurwaarden. $1^{\text {st }}$ ed. Utrecht, the Netherlands: KNNV Publishing, Utrecht, 56 pp.

13. Coesel, P.F.M., Kwakkestein, R. \& Verschoor, A. 1978. Oligotrophication and eutrophication tendencies in some Dutch moorland pools, as reflected in their desmid flora. Hydrobiologia, 61: 21-31.

14. Compère, P. 2001. Flore pratique des algues d'eau douce de Belgique. Tome 5 Desmidiees 1: Mesotaeniaceae, Gonatozygaceae, Peniaceae, Closteriaceae. Meise, BEL, Jardin Botanique National de Belgique, 69 pp.

15. Davis, C.C. 1955. The marine and freshwater plankton. Mishigan State University Press, Mishigan, 562 pp.

16. DGWM (Ministry of Agriculture and Forestry, General Directorate of Water Management), 2015a. Project of Determining Sensitive Area and Water Quality Targets based on River Basin in Turkey. Final Report, Vol-1.

17. DGWM (Ministry of Agriculture and Forestry, General Directorate of Water Management), 2015b. The Communique on Sampling and Biological Sampling from Surface Waters, Groundwater and Sediment. Official Gazette, Number: 29274.

18. DSİ (Turkish Acronym for State Hydraulic Works), 2014. Water and DSI: 60 Years (1954-2014) Full of Realized Projects. Booklet by Ministry of Forestry and Water Affairs (English), Ankara.

19. Edmondson, W.T. 1959. Freshwater Biology. John Wiley and Sons, New York, 124 pp.

20. Gąbka, M. 2007. Distribution of Chara tenuispina A. Braun 1835 (Characeae) in Poland. Oceanological and Hydrobiological Studies, 36(1): 241-248. 
21. Gayathri, N., Rajashekhar, M., Fatima, K., Vijaykumar, K., Ratandeep \& Baburrao, M. 2011. Hydrochemistry and plankton diversity of Tungabhadra reservoir Bellary district, Karnataka. International Journal of Zoology Research, 1(1): 01-07.

22. Gönülol, A., Öztürk, M. \& Öztürk, M. 1996. A check-list of the freshwater algae of Turkey. Ondokuz Mayls University Faculty of Arts and Sciences Journal of Science, 7(1): 8-46.

23. Guiry, M.D. \& Guiry, G.M. 2021. AlgaeBase. World-wide electronic publication, National University of Ireland, Galway. http://www.algaebase.org (Date accessed: 20 January 2021).

24. Hansen, G., Stastny, J., Moestrup, Ø. \& Lundholm, N. 2018. Diversity and conservation of desmids in Bornholm, Denmark - revisiting after 130 years. Nordic Journal of Botany, 36(10): 1-14. https://doi.org/10.1111/njb.01994

25. Huber-Pestalozzi, G. 1982. Das phytoplankton des süsswassers systematik und biologie. Teil 8, 1. Hälfte, Conjugatophyceae Zygnematales und Desmidiales (excl. Zygnemataceae), E. Schweizerbarth'sche Verlagsbuchhandlung (Nagele u. Obermiller), Stuttgart, $543 \mathrm{pp}$.

26. John, D.M., Whitton, B.A. \& Brook, A.J. 2003. The Freshwater Algal Flora of the British Isles: An Identification Guide to Freshwater and Terrestrial Algae. The Natural History Museum and The British Phycological Society, Cambridge: Cambridge University Press, 714 pp.

27. Kadlubowska, J.Z. 1984. Süßwasserflora von Mitteleuropa 16. Chlorophyta VIII: Conjugatophyceae I: Zygnemales. Jena, DEU, VEB Gustav Fischer Verlag, 531 pp.

28. Kolkwitz, R. \& Krieger, H. 1971. Dr L. Rabenhorst's Kryptogamen-Flora 13. 2. Abteilung. Zygnemales: Lieferung 1-4, New York, USA, Johnson reprint corporation, $163 \mathrm{pp}$.

29. Kouwets, F. 2008. The species concept in desmids: the problem of variability, infraspecific taxa and the monothetic species definition. Biologia, 63: 881-887.

30. Kravtsova, L.S., Mizandrontsev, I.B., Vorobyova, S.S., Izhboldina, L.A., Mincheva, E.V., Potyomkina, T.G., Golobokova L.P., Sakirko, M.V., Triboy, T.I., Khanaev, I.V., Sherbakov, D.Y. \& Fedotov, A.P. (2020). Influence of water motion on the spatial distribution of Spirogyra in Lake Baikal. Journal of Great Lakes Research, 46(1): 2940.

31. Lee, O.M. 2015. Additions to the six taxa of the genus Cosmarium (Desmidiaceae, Charophyta) in Korea. Journal of Ecology and Environment, 38: 629-636.

32. Lenzenweger, R. 1996. Bibliotheca Phycologica. band 101. Desmidiaceenflora von Österreich. Teil 1, Berlin, DEU, Cramer, 162 pp.

33. Lenzenweger, R. 1997. Bibliotheca Phycologica, band 102. Desmidiaceenflora von Österreich. Teil 2, Berlin, DEU, Cramer, $216 \mathrm{pp}$.

34. Lenzenweger, R. 1999. Bibliotheca Phycologica. band 104. Desmidiaceenflora von Österreich. Teil 3, Berlin, DEU, Cramer, $218 \mathrm{pp}$.
35. Lenzenweger, R. 2003. Bibliotheca Phycologica. band 111. Desmidiaceenflora von Österreich. Teil 4, Berlin, DEU, Cramer, 87 pp.

36. Lind, E.M. \& Brook, A.J. 1980. Desmids of the English Lake District. Freshwater Biological Association Scientific Publication, No: 42, Ambleside, Cumbria, 123 pp.

37. Maraşlığlu, F. \& Gönülol, A. 2021. Turkishalgae electronic publication, Çorum, Turkey. http://turkiyealgleri.hitit.edu.tr (Date accessed: 15 January 2021).

38. Maraşlığlu, F. \& Soylu, E.N. 2018. New Diatom Records for Turkish Freshwater Algal Flora from Lakes Ladik (Samsun, Turkey) and Hazar (Elazı̆̆g, Turkey). Turkish Journal of Fisheries and Aquatic Sciences, 18(3): 463-474. https://doi.org/10.4194/1303-2712-v18_3_12

39. Novis P.M. 2004. New records of Spirogyra and Zygnema (Charophyceae, Chlorophyta) in New Zealand. New Zealand Journal of Botany, 42: 139-52.

40. Oliveira I., Bicudo C. \& Moura C.W.N. 2010. New records of filamentous desmids (Desmidiaceae, Zygnematophyceae) from Bahia state, Brazil. Acta Botanica Brasilica, 24(4): 1017-1026. https://doi.org/10.1590/S0102-33062010000400016

41. Özer, T., Erkaya, İ.A., Udoh, A.U., Akbulut, A., Yıldız, K. $\&$ Şen, B. 2012. New records for the freshwater algae of Turkey (Tigris Basin). Turkish Journal of Botany, 36(6): 747-760.

42. Öztürk, M., Gönülol, A. \& Öztürk, M. 1995a. A new record for the algal flora of Turkey: Pleurotaenium trabecular (Ehr.) ex Nägeli (Desmidiaceae). Ondokuz Mayls University Faculty of Arts and Sciences Journal of Science, 6(1): 212-218.

43. Öztürk, M., Gezerler-Şipal, U., Güner, H., Gönülol, A. \& Aysel, V. 1995b. A new record for the algal flora of Turkey: Closterium kuetzingii Bréb. var. kuetzingii (Conjugatophyceae, Desmidiales). Ege Journal of Fisheries and Aquatic Sciences, 12(1-2): 145-149.

44. Sevindik, T.O., Çelik, K. \& Gönülol, A. 2010. Twenty-four new records for the freshwater algae of Turkey. Turkish Journal of Botany, 34: 249-259.

45. Sevindik, T.O., Çelik, K. \& Gönülol, A. 2011. Twenty New Records for Turkish Freshwater Algal Flora from Çaygören and Ikizcetepeler Reservoirs (Balıkesir, Turkey). Turkish Journal of Fisheries and Aquatic Sciences, 11: 399-406. https://doi.org/10.4194/1303-2712-v11 309

46. Sevindik, T.O., Gönülol, A., Önem, B., Tunca, H. \& Arabac1, S. 2015. Thirty new records for Turkish freshwater algal flora from Danamandıra Ponds (Silivri, İstanbul) and North Mollaköy Lake (Sakarya). Biological Diversity and Conservation, 8(2): 4-15.

47. Sevindik, T.O., Gönülol, A., Tunca, H., Gürsoy, N.Y., Küçükkaya, Ş.N. \& Durgut Kınalı, Z. 2017. Nineteen new records for Turkish freshwater algal flora from Lake Taşkısığı and Lake Little Akgöl. Biological Diversity and Conservation, 10(1): 69-78.

48. Sherwood, A.R., Neumann, J.M., Dittbern-Wang, M. \& Conklin, K.Y. 2018. Diversity of the green algal genus Spirogyra (Conjugatophyceae) in the Hawaiian Islands. Phycology, 57(3): 331-344. 
49. Shukla S.K., Shukla C.P. \& Misra P.K. 2008. Desmids (Chlorophyceae, Conjugales, Desmidiaceae) from Foothills of Western Himalaya, India. Algae, 23(1): 1-14.

50. Šimek, O. 1997. Changes in desmid flora of the nature reserve Režabinec in South Bohemia after 30 years of intense environmental agriculture. Algological Studies, 87: 59-85.

51. Stancheva, R., Hall, J.D., Mccourt, R. \& Sheath, R.G. 2013. Identity and phylogenetic placement of Spirogyra species (Zygnematophyceae, Charophyta) from California streams and elsewhere. Journal of Phycology, 49: 588-607.

52. Štastný, J. 2009. The desmids of the Swamp Nature Reserve (North Bohemia, Czech Republic) and a small neighbouring bog: species composition and ecological condition of both sites. Fottea, 9: 135-148.

53. Şahin, B. \& Akar, B. 2007. The desmid flora of some high mountain lakes of the Turkish Doğu Karadeniz region. Pakistan Journal of Botany, 39: 1817-1832.

54. Şahin, B. \& Akar, B. 2019. New desmid records from high mountain lakes in Artabel Lakes Nature Park, Gümüşhane, Turkey. Turkish Journal of Botany, 43: 570-583. https://doi.org/10.3906/bot-1810-71

55. Şahin, B. 1998. Some new records of desmids from Turkey. Pakistan Journal of Botany, 30: 7-13.

56. Sahin, B. 2000. Some new desmids records for freshwater algal flora of Turkey. Flora Mediterranea, 10: 223-226.

57. Şahin, B. 2002. Contribution to the desmid flora of Turkey. Algological Studies, 107: 39-48.

58. Şahin, B. 2005. A preliminary checklist of desmids of Turkey. Cryptogamie, Algologie, 26(4): 399-415.
59. Sahin, B. 2007. Two new records for he freshwater algae of Turkey. Turkish Journal of Botany, 31: 153-156.

60. Sahin, B. 2009. Contribution to the desmid flora of Turkey. Turkish Journal of Botany, 33: 457-460. https://doi.org/10.3906/bot-0809-15

61. Şahin, B., Akar, B. \& Barinova, S. 2020. Non-diatom algae of the high mountain protected lakes in the Artabel Lakes Nature Park, Gümüşhane, Turkey. Botanica Pacifica, 9(2): 47-59. https://doi.org/10.17581/bp.2020.09206

62. Taşkın, E., Akbulut, A., Yıldız, A., Şahin, B., Şen, B., Uzunöz, C., Solak, C., Başdemir, D., Sevik, F., Sönmez, F., Açkgöz, I., Pabuccu, K., Öztürk, M., Alp, M.T., Albay, M., Çakır, M., Özbay, Ö., Can, Ö., Akçaalan, R., Atıcı, T., Koray, T., Özer, T., Karan, T., Aktan, Y. \& Zengin, Z.T. 2019. Türkiye suyosunlarl listesi (Turkey algae list). Ali Nihat Gökyiğit Vakfı Yayını, İstanbul. 804 pp.

63. Varol, M. \& Fucikova, K. 2015. Four new records for the freshwater algae of Turkey. Journal of Limnology and Freshwater Fisheries Research, 1(2): 83-88.

64. Varol, M. \& Şen, B. 2016. New records of Euglenophyceae for Turkish freshwater algae. Turkish Journal of Fisheries and Aquatic Sciences, 16(2): 219-225.

65. Volkova, E.A., Bondarenko, N.A. \& Timoshkin, O.A.Y. 2018. Morphotaxonomy, distribution and abundance of Spirogyra (Zygnematophyceae, Charophyta) in Lake Baikal, East Siberia. Phycologia, 57(3): 298-308.

66. Yüce, A.M. \& Ertan, Ö.O. 2014. A new record for the freshwater algae of Turkey. Scientific Research Journal, 2(4): $21-22$ 